\title{
How to get in and out of the skull: from tumi to "hammer and chisel" to the Gigli saw and the osteoplastic flap
}

\author{
James Tait Goodrich, M.D., Ph.D. \\ Division of Pediatric Neurosurgery, Leo M. Davidoff Department of Neurological Surgery, Children's \\ Hospital at Montefiore, and Departments of Pediatrics and Plastic and Reconstructive Surgery, Albert \\ Einstein College of Medicine, Bronx, New York
}

\begin{abstract}
Making "holes in the skull" is an ancient art and by some is considered the second oldest profession in the world - the first being prostitution. Early surgeons, and later on neurosurgeons, devised a number of ingenious ways to make a hole in the skull or elevate a depressed skull fracture. Trephined skulls from antiquity have now been found in most parts of world, showing that the art of trephining is not only ancient but clearly widespread. Beginning with antiquity the author traces the development of this surgical skill by reviewing the various tools used and surgical designs to perform what is now called a craniotomy. (http://thejns.org/doi/abs/10.3171/2014.2.FOCUS13543)
\end{abstract}

KEY WORDS • craniotomy $\quad$ osteoplastic craniotomy $\bullet \quad$ cranioplasty
history of neurosurgery $\bullet$ head trauma

$\mathrm{S}$ URGICAL skills have been around since human beings walked erect and developed hand skills that allowed for crafting, harvesting, and the design of tools and weapons. Ancient man also realized that the best way to take your enemy down was a blow to the head. Throughout the world are many known examples of "skull crushers," weapons solely designed to crush the skull of the enemy or an animal for food. Early man also needed to know how to treat or correct a head injury to save a friend or colleague. Surgery has been defined as the art or practice of treating injuries, deformities, and other disorders by manual operation or instrument appliances. The word "surgery" is derived from the Greek

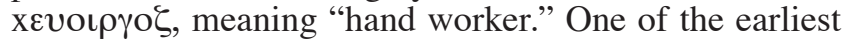
skills developed by Homo sapiens was the skill of drilling a hole in the head-what we now call a trephination. Archeological research has now identified trephined skulls that date back to at least $12,000 \mathrm{BC}$.

In reviewing some of these skulls there is clear evidence of postmorbid bone healing. These findings reveal that these ancient surgeons could not only perform trephinations but could do it in such a fashion that the injured person survived their injury to the head. Historians have speculated that trephination was also done for religious reasons, treatment of headaches, and release of "demons or evil spirits." There is unfortunately no material that documents any of these concepts.

The earliest tools that we know of for performing a trephination were formed from obsidian or chert material, materials commonly used to make pointed projectiles. There are numerous examples of chert (flint or stone) or obsidian (volcanic glass) that have been knapped and at- tached to a handle. By continued scrapping or drilling of the bone, a surgeon could gradually remove skull bone to the level of the dura mater (Figs. 1 and 2).

The technique for performing a trephination in the ancient world involved basically 3 different techniques. The "scraping" technique, of which an example is shown in Fig. 2. This technique was typically done with a copper or bronze instrument called the tumi. A "crosshatch" cut, where 4 parallel cuts were made, allowed the surgeon to remove a square or rectangular portion of skull. A third technique involved the use of a trebrvm modeled after a carpenter's awl; a piece of flint or chert was placed into the rotating handle of the device and a series of drill holes were made and then connected. In looking back over history it was commonly the case that early surgeons basically adopted tools that came from the kitchen or the workshop. In looking at museum collections of surgical instruments, most are clearly adaptations of household items, only a bit more ornate in style based on the wealth of the surgeon (Fig. 3).

Ancient surgeons were also quite inventive in dealing with "holes in the head" such as bone defects left from traumatic injuries. In the collection of the Museum of Gold in Lima, Peru, is an exceptional example of "gold" cranioplasty that is well healed; because gold was used, the individual was likely of noble status. Over the centuries many different materials have been used to fill in holes in the head. These materials range from various metallic implants to coconut shells and bones from animals among other materials.

War has always been a fruitful time for a surgeon to learn and refine his operative skills. With the forma- 


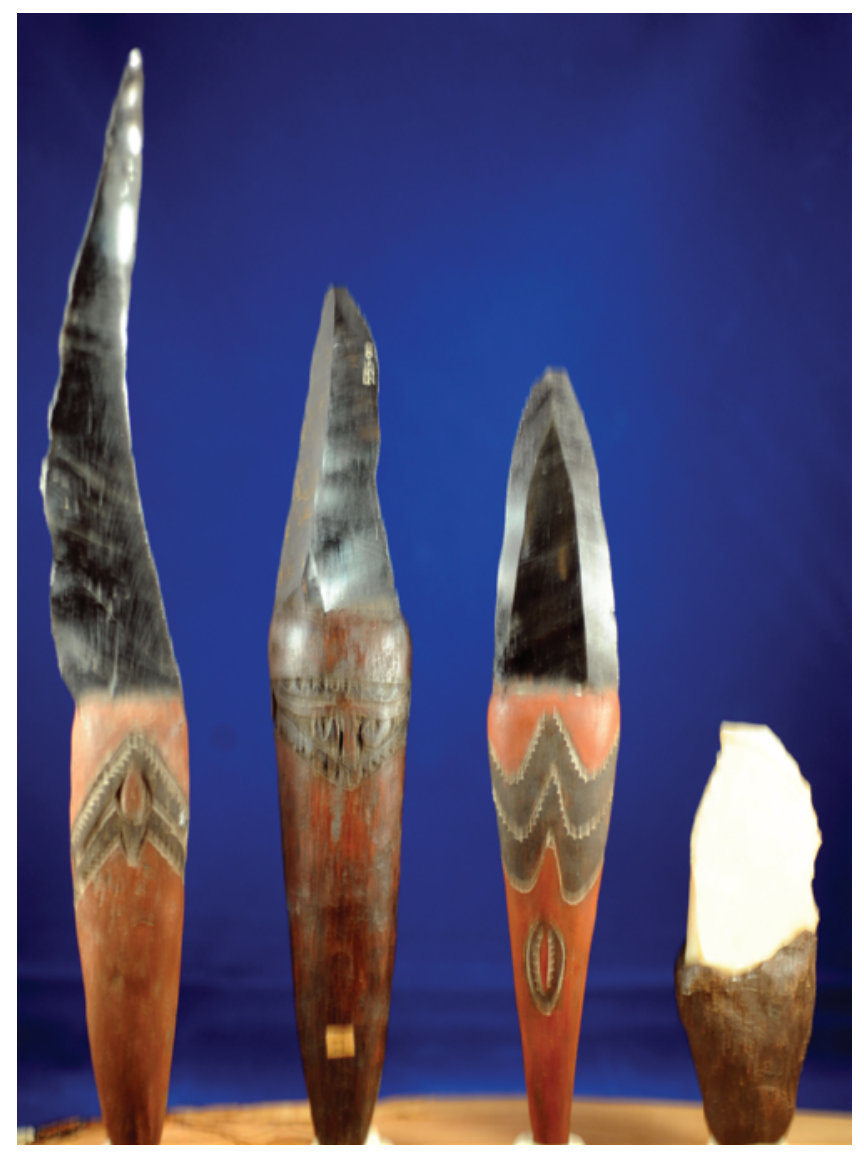

FIG. 1. Four examples of early "tools" that could be used to perform a trephination. The three to the left are obsidian glass attached to a gourd handle and held with pinesap. The one on the right is fashioned from chert, a stone or flint that has been knapped to form sharp edges, and the handle is made of hardened bees wax. These items are from the author's personal collection.

tion of the Roman Empire and the many military engagements, surgeons were able to develop surgical skills and also learn human anatomy. During the Greco-Roman era, medicine became more developed and codified, and one of the best examples of a surgeon who took advantage of this was Galen of Pergamon (130 AD-200 AD). Galen was an accomplished anatomist, a skilled surgeon, and the developer of a huge collection of surgical, medical, and physiological treatises. This was the period when surgical instrumentation moved from glass, stone, chert, and flint materials to iron, bronze, and copper, providing the surgeon more versatility in design as well as better and more solid material to work with. ${ }^{21}$

The medical and surgical writings developed during the Greco-Roman era (circa $450 \mathrm{BC}-6$ th century $\mathrm{AD}$ ) became codified and underwent little change until the Renaissance. In the Byzantine era, the Islamic culturesand in particular two figures, Avicenna (980-1037 AD) and Albucasis (Abul Qasim, 936-1013 AD) - continued to codify surgical treatments and medical practice for physicians and surgeons. ${ }^{3-5}$ The use of surgical cautery, the application of a red-hot instrument to stop bleeding, became popular in the general Islamic surgical practice. In regard to trephination, there are very few examples in the Arabic
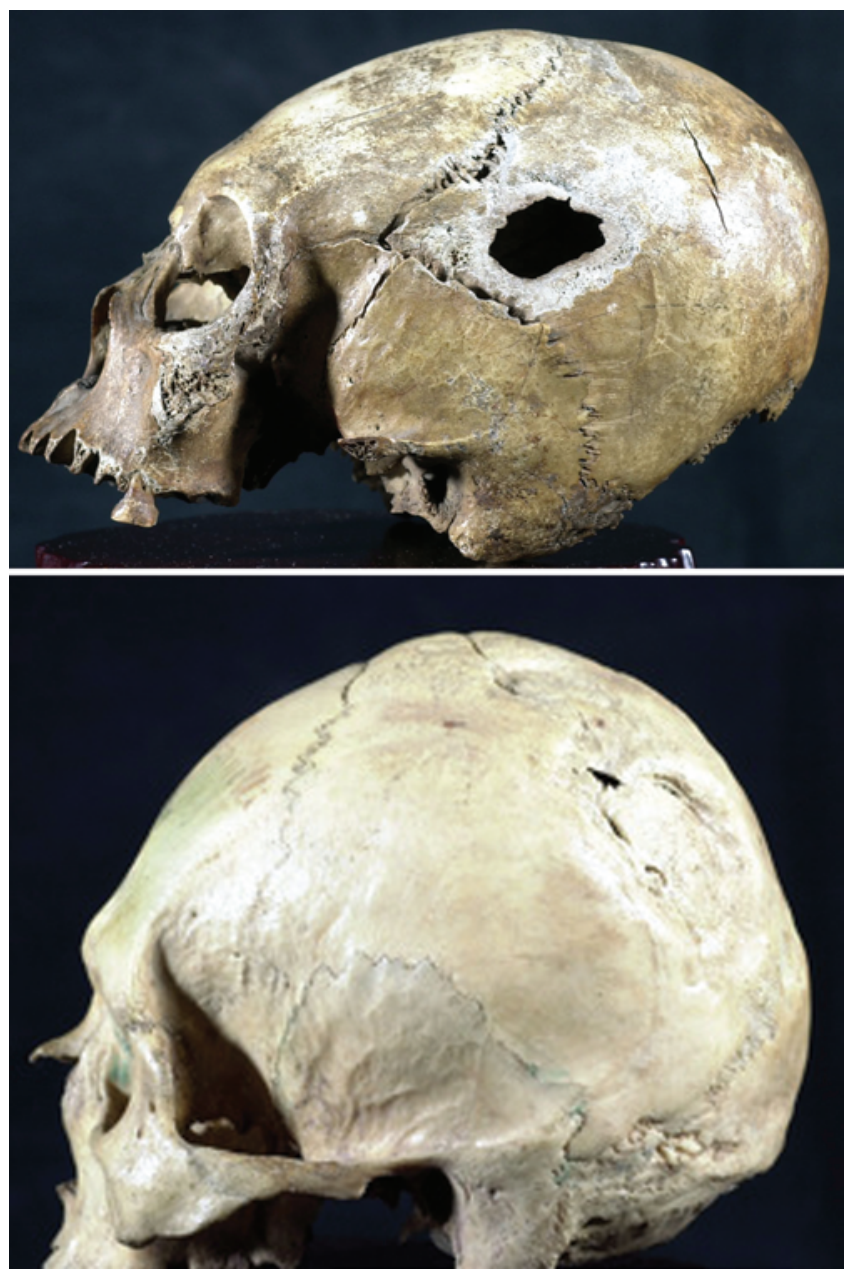

Fig. 2. Two examples of trephined skulls. In the upper image, one can see a trephination over the left temporal region that shows no signs of healing. The skull in the lower image has a large left parietal trephination with clear signs of antemortem healing. These items are from the author's personal collection.

literature. Review of the literature from the "The Golden Age of Islam" (circa 600-1000 AD) indicates that the treatment and techniques for brain injury relied mostly on the writings of Paul of Aegina (625-690 AD), a prominent 6th century surgeon. ${ }^{1,2}$ Hippocrates had opined in the 4th century BC that no surgeon should consider going deeper than the dura mater as the risks were enormous. A surgeon could elevate a depressed skull fracture or remove a cephalohematoma, but removal of a subdural or intraparenchymal hematoma was virtually forbidden-the risks were considered to be too high. Examples of Byzantine/ Islamic instruments are shown in Fig. 4.

In the European medieval period the surgical techniques for dealing with head injuries remained firmly based on the Hippocratic concepts, which were later codified by the Islamic scholars. Instrument design remained rather crude, with most craniectomy methods based on the "hammer and chisel" technique. ${ }^{35}$ In Europe the surgeon was basically an itinerant "barber-surgeon" traveling from town to town and offering whatever skills he had. Minimal anesthesia was available, mostly just al- 


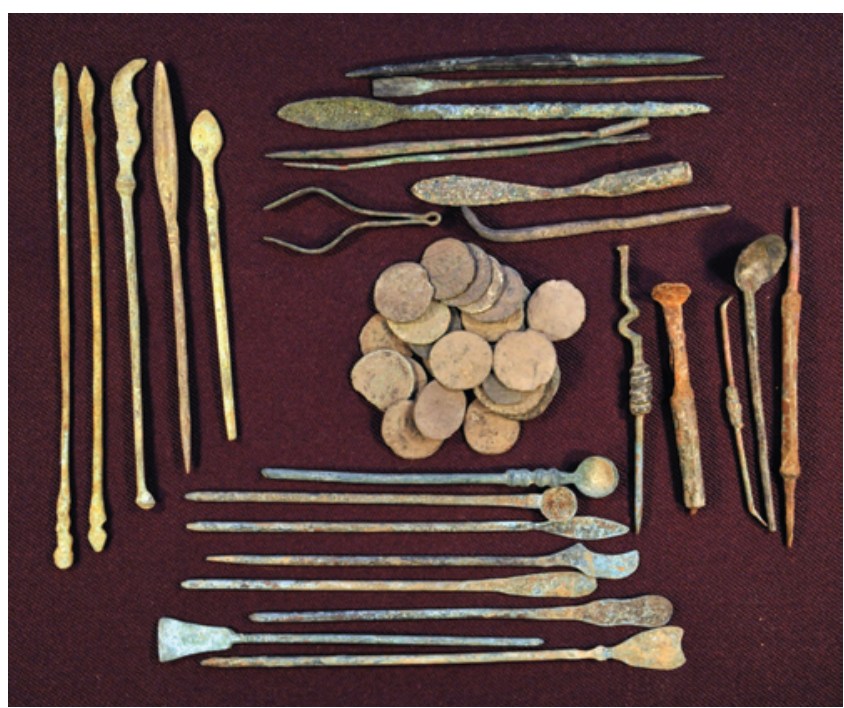

FIG. 3. A collection of scalpels, probes, and spatulas used during the Roman Empire; many are likely adapted from household instruments. These instruments date from the 2nd century BC to the 3rd century AD. The coins date to the 2 nd century AD. These items are from the author's personal collection.

cohol and opium. Antisepsis-other than the occasional application of wine to the wound-was unheard of. Medieval neurosurgical techniques could best be described as cruel and brutal (Fig. 5).

In the later Middle Ages the blacksmith became a more skilled appliance and device maker, using betterquality iron ore and other materials. Blacksmiths typically forged horseshoes and farming equipment along with instruments mostly designed for cooking and cosmetic uses, and they also forged instruments for the surgeon

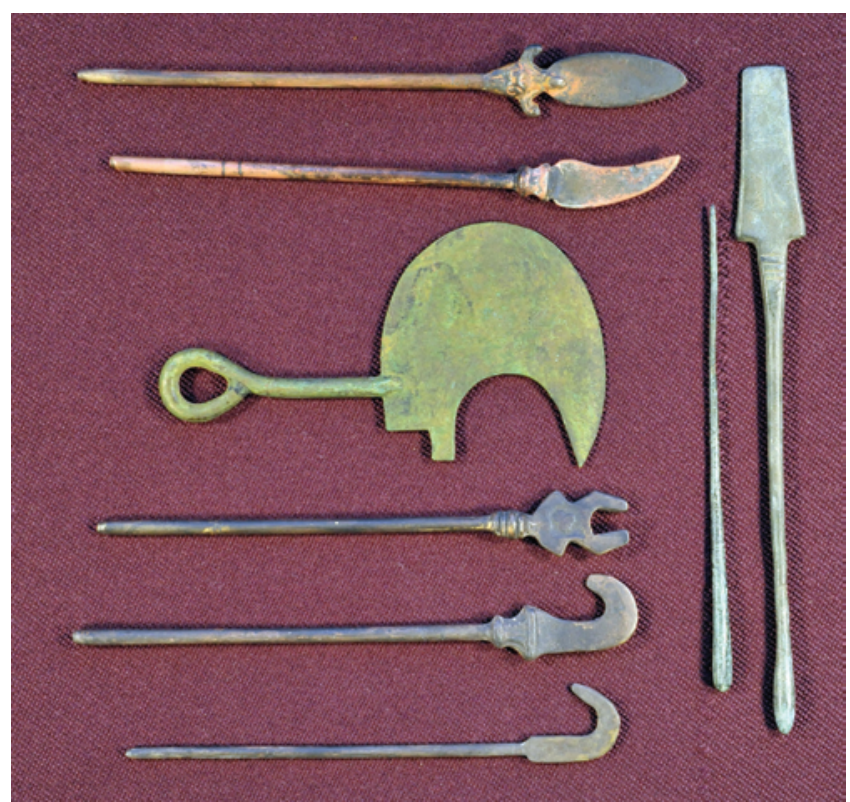

Fig. 4. Some examples of Byzantine/lslamic instruments used for cautery and some surgical instruments for the treatment of hydrocephalus-mostly based on the work of Albucasis. These items are from the author's personal collection.
(Fig. 6). The Renaissance, and particularly the 16th century, saw significant advances in the design of surgical instruments. Surgeons became more educated and even obtained (or began to obtain) university degrees.

The 16th century ushered in the "tripod"-style trephine for elevating a depressed skull fracture. An early example of this tripod style was illustrated in Hans von Gersdorff's (1455-1529) book on surgery (1517) (Fig. 7). ${ }^{19,36}$ Interestingly, very few of these devices remain, even in museum collections. I have only seen one tripod type of trephine offered for sale in 35 years and it was a very primitive style from the 18 th century.

To Jacopo (Giacomo) Berengario da Carpi (14701550) we owe the credit for providing the first printed textbook solely devoted to the treatment of head injuries. Berengario was a skilled autodidactic anatomist and one who performed his own anatomical dissection rather than relying on codified doctrines of Galen and the Islamic schools. These anatomical doctrines along with their errors remained virtually unchanged from the 2nd century AD until the time of the Renaissance. In his Tractatus, Berengario reveals some very interesting and innovative instrument designs for doing a bur hole or craniectomy (Fig. 8). ${ }^{9}$ Berengario offers the reader over 8 bit designs that can be interchanged on a hand brace-not too dissimilar to what we call the Hudson brace today. Berengario developed a prominent surgical career caring for a

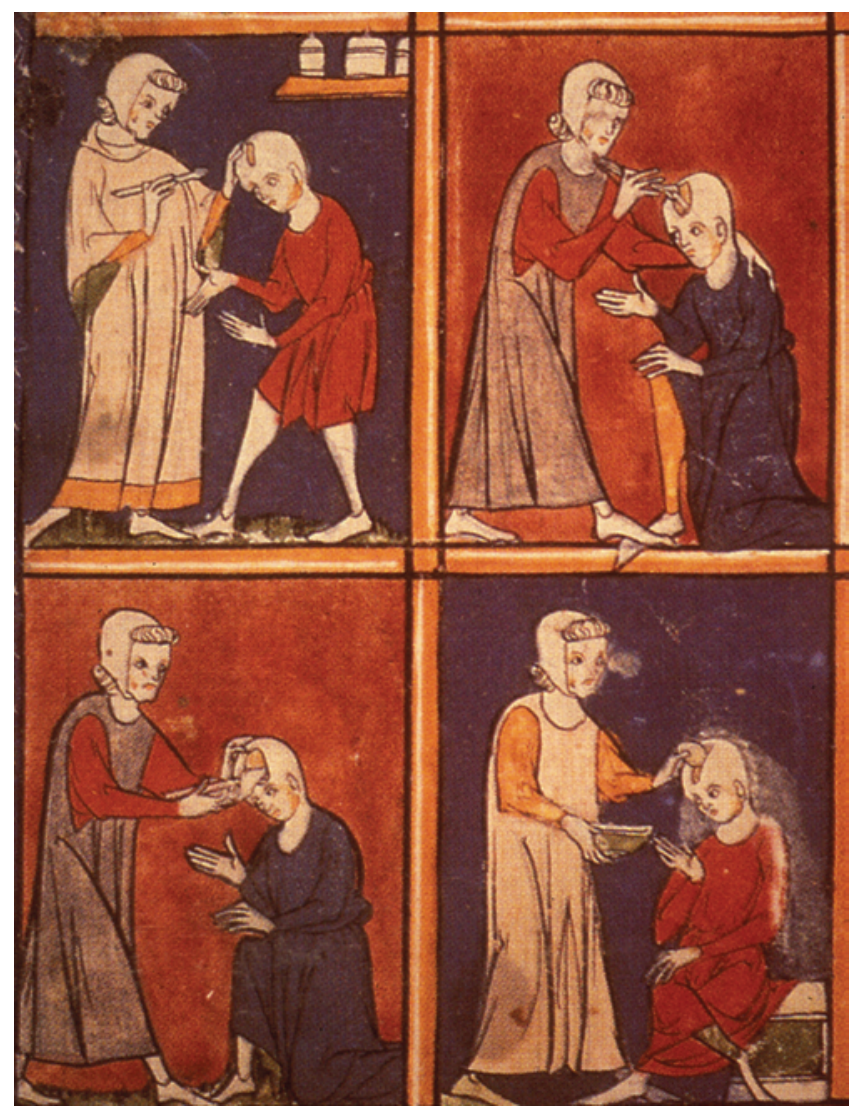

FIG. 5. The "hammer and chisel" technique for performing a craniectomy. This image is from Roger of Salerno and dates to the 13th century. Courtesy of the Sloane Collection, British Museum, London, England. 


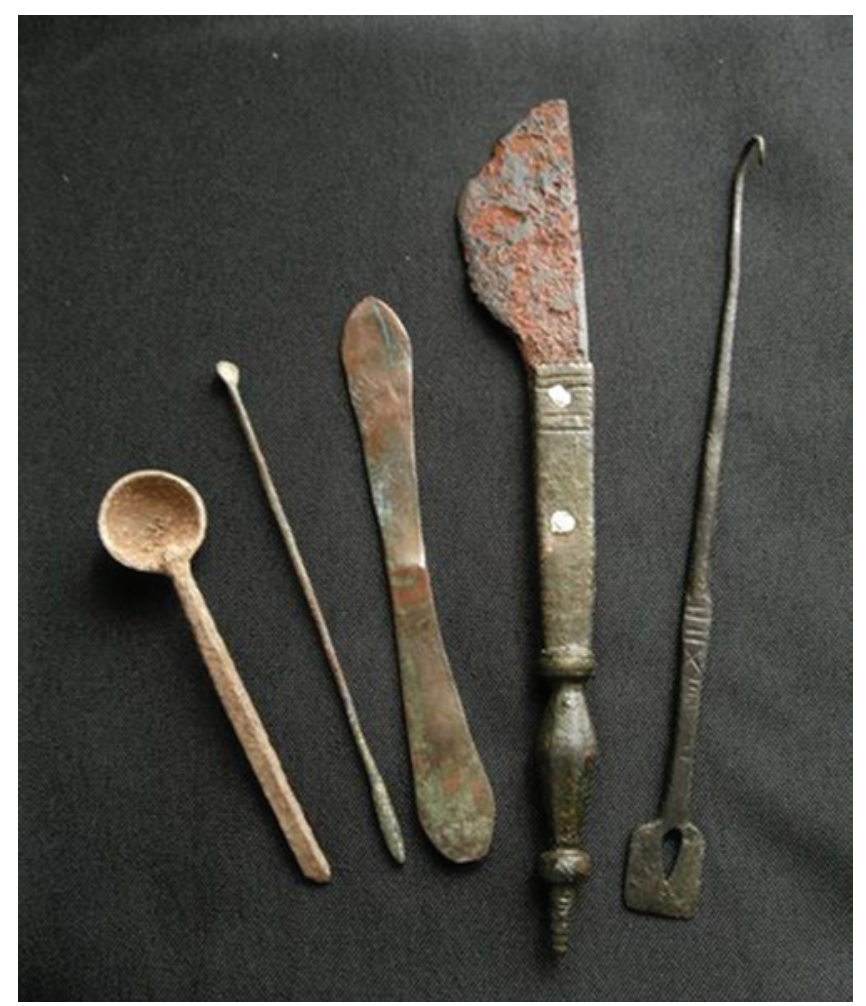

FIG. 6. Some examples of English medieval surgical instruments. IIlustrated here are examples of a probe, scalpel, vein hook, and elevator/ spatula. Small measuring scoops were used for the pharmaceuticals. A close look at the instrument designs reveals that these tools are mostly adaptations from household implements. These items are from the personal collection of the author.

number of eminent individuals. An important neurosurgical historical case for Berengario involved a Medici who had sustained an occipital fracture from a lance during a jousting event.

Following along on the theme of a talented surgeon designing his own trephine brace and interchangeable bits was Andrea della Croce (1509?-1589). In his seventh book chapter (Libri VII), della Croce provides a series of elegant illustrations of performing a trephination in a well-furnished Renaissance noble's home. ${ }^{16}$ The surgery was performed on the homeowner's bed with his dog lying nearby on the floor chewing on a rat. Della Croce detailed an elegant brace design, again with a series of interchangeable trephine bits (Fig. 9).

The first systematic surgical text to be printed in English was provided by Peter Lowe (1550-1612). Most medical and surgical works at this time were published in Latin, so only the educated physician could read them. The book is interesting to read, as Lowe wrote in a narrative style in the form of a dialogue between himself and his son..$^{29}$ In discussing a trephination he noted that it was "best to trepan when dura is intact"-sage advice that dates back to Hippocrates. In looking at his Discovrse of the Whole Art of Chyvrgerie..., Lowe has illustrated his armamentarium of neurosurgical instruments, including a Hudson brace-style trephine with a series of interchangeable bits. He also illustrates a series of elevators and a bone rongeur (Fig. 10). In addition, we see here for the

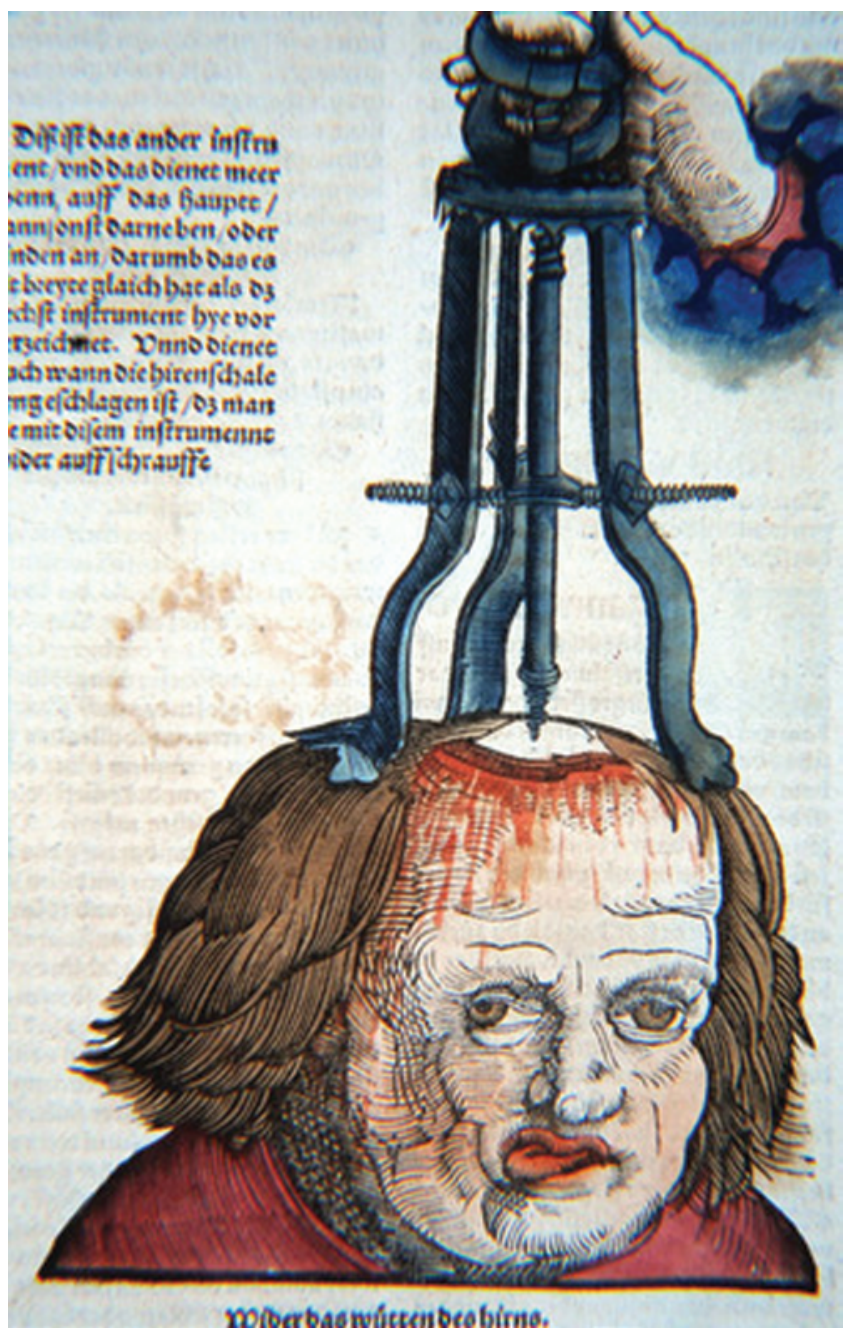

Fig. 7. A example of the "tripod" trephine being used by a prominent Renaissance surgeon-Hans von Gersdorff. Interesting to note that the artist is also illustrating signs of a third nerve palsy. Image courtesy of the Reynolds Library, University of Alabama, Birmingham, Alabama.

first time an instrument called a "tiere froid" which is basically a corkscrew-like device, which the surgeon screws into the depressed fracture and then pops back out. This
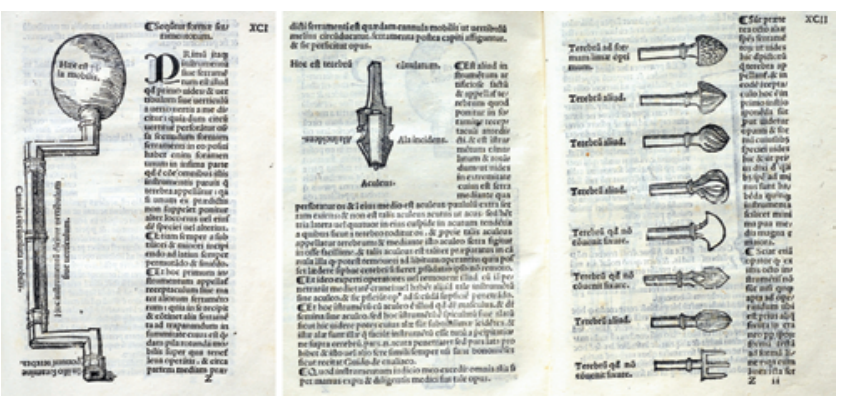

FIG. 8. Left: Berengario's design for a trephine brace able to accept interchangeable bur bits. Right: Facing pages, with the right-hand page showing Berengario's illustration of the various trephine bits that he had designed. He also designed a triangular head shape to prevent plunging into the brain. From Berengario da Carpi J: Tractatus de Fractura Calvae Sive Cranei. Bologna: Hieronymus de Benedictus, 1518. 


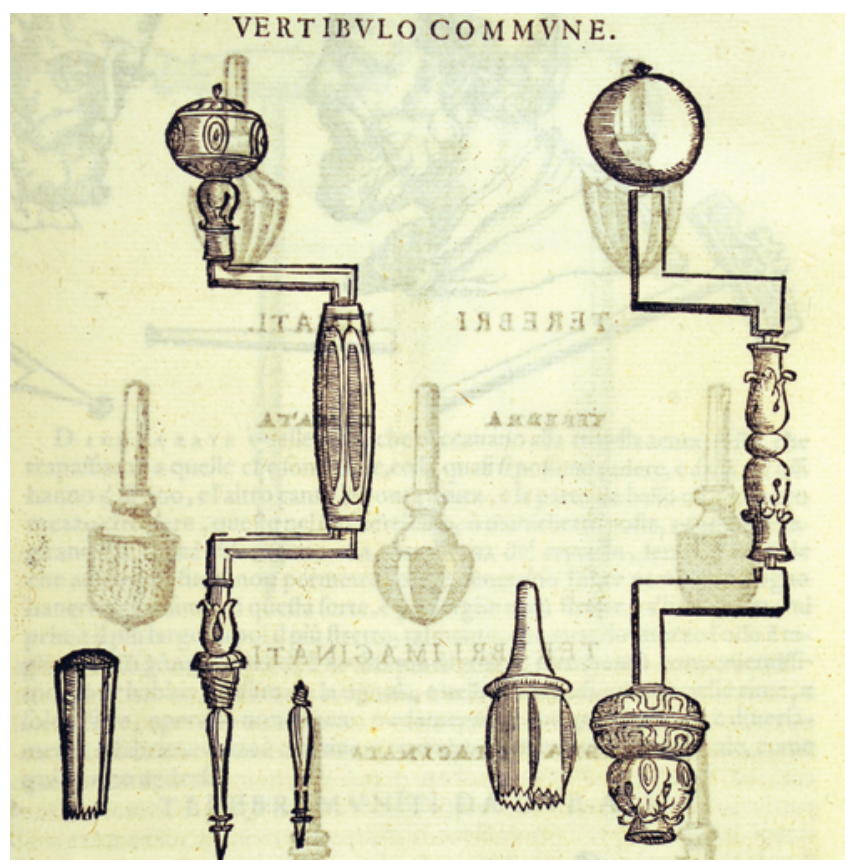

FIG. 9. Della Croce's design for a trephine brace with interchangeable bur designs. From della Croce GA: Chirurgiae Libri Septem. Venice: Jordanus Zilettus, 1573.

tool style remained popular until the end of the 18th century. One can only image the consequences of drilling into depressed fracture bone and what the outcomes were like.

A popular and well-known early English surgeon of the Elizabethan period was William Clowes the elder (circa 1543 or 1544-1604). Clowes published one of the first surgical texts to be written in English in $1596 .{ }^{14}$ As was common, Clowes refined his surgical skills as an Army surgeon in the European conflicts-a significant one included defeating the Spanish Armada. Clowes became surgeon at St. Bartholomew's and went on to comment on the poor surgical skills of his brethren "... though bad surgeons, he says, slew more than the enemy." 14 A review of his surgical armamentarium indicates he preferred the tripod-style trephine for elevating a depressed skull fracture. Clowes also used a trephine brace with interchangeable trephine bits. When discussing surgical technique, Clowes offered the following to a surgeon in training: "Those which are Masters and Professors chosen to performe the like operation ought indeede to have a Lyons heart, a Ladies Hand and a Hawkes eye, for that is a work of no small importance." 14

John Woodall (circa 1556-1663) was a military surgeon who worked for the East India Company and spent a good deal of time on ships rolling and lurching in the seas. In his The Surgeon's Mate (1617), he modified the trephine crown portion by adding a center pin with a sharp point. ${ }^{38}$ This point could be anchored into the skull at the beginning of the trephination. This maneuver was designed to prevent slippage on a "bloody skull" and a rolling deck (Fig. 11). Woodall also modified his technique by putting the top handle of the brace against his chest so he could hold steady with one hand while using the other to turn the brace. Woodall also felt that anyone

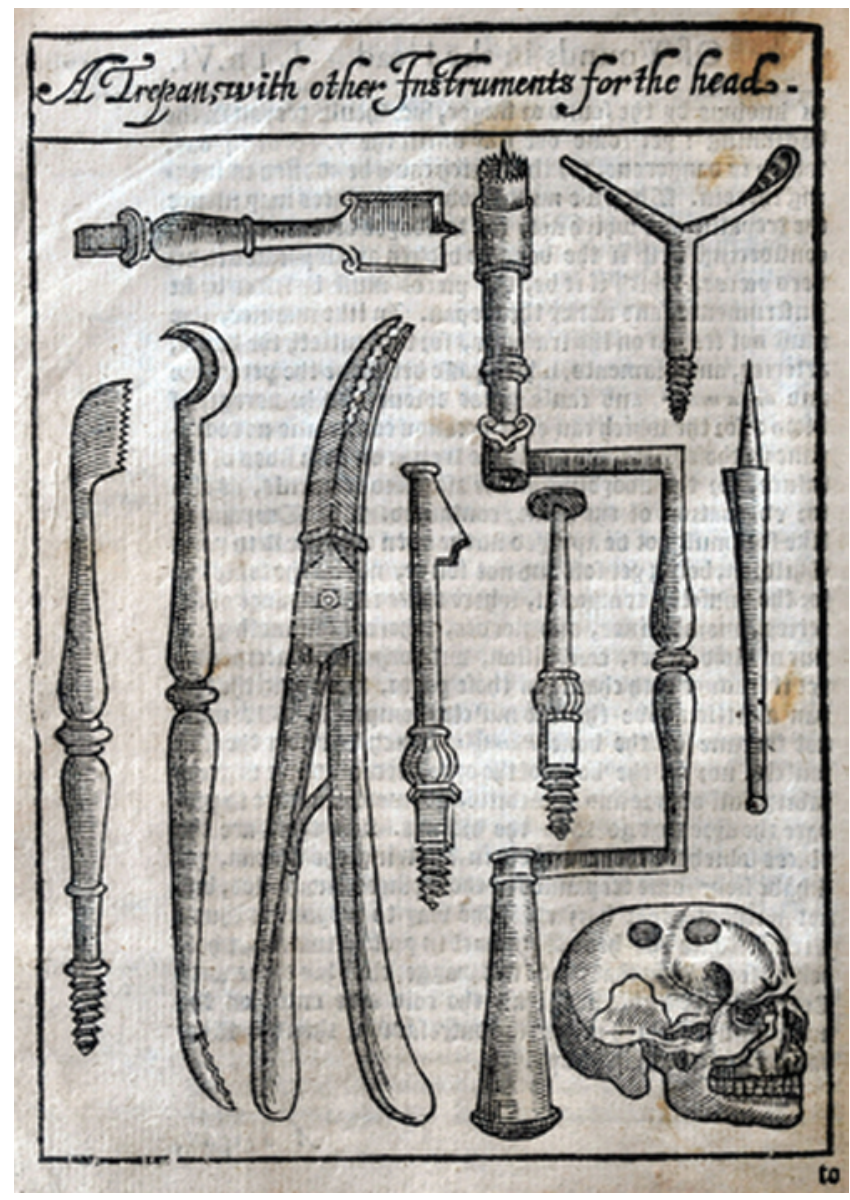

Fig. 10. Various trephines, bone rongeurs, and scrapers for performing a trephination-designed by Lowe. In the upper right corner is a "tiere froid" type of skull fracture elevator. From Lowe P: A Discourse of the Whole Art of Chyrvrgery. Wherein is Exactly Set Down the Definitions Causes, Accidents, Prognostications, and Cures of All Sorts of Diseases, both in Generall and Particular, Which at Any Time Hertofore Have Been Practiced ... Whereunto is Added the Rule of Making Remedies Which Chyrurgions doe Commonly Use, With the Prefaces of Divine Hippocrates. The Fourth Edition, Corrected, and Much Amended. London: R. Hodgkinsonne, 1654.

going to do a trephination should first practice on a sheep or calf head!

I therefore would advise a young Artist to make some experience first upon a calves head, or a sheep's head, till he can well and easily take out a piece of the bone; so shall he the more safely do it to a man without error when occasion is. ${ }^{38}$

A popular modification to Woodall's trephine style was introduced by René Garengeot (1688-1759), a prominent French surgeon. ${ }^{22}$ As illustrated in Fig. 12, Garengeot preferred to rest his chin on the brace handle and use the weight of the head to help to drive the trephine bit. (See also Fig. 13.) Garengeot was also one of the earliest surgeons to appreciate the "lucid interval" in head trauma.

The 18th century brought about the more compact traveling neurosurgical sets. These sets were often in elaborate leather-encased boxes with handles and clasps made of brass. The trephines became now more commonly the "one-handed" type, allowing the surgeon to perform the procedure with a single hand. The handles are T-shaped 


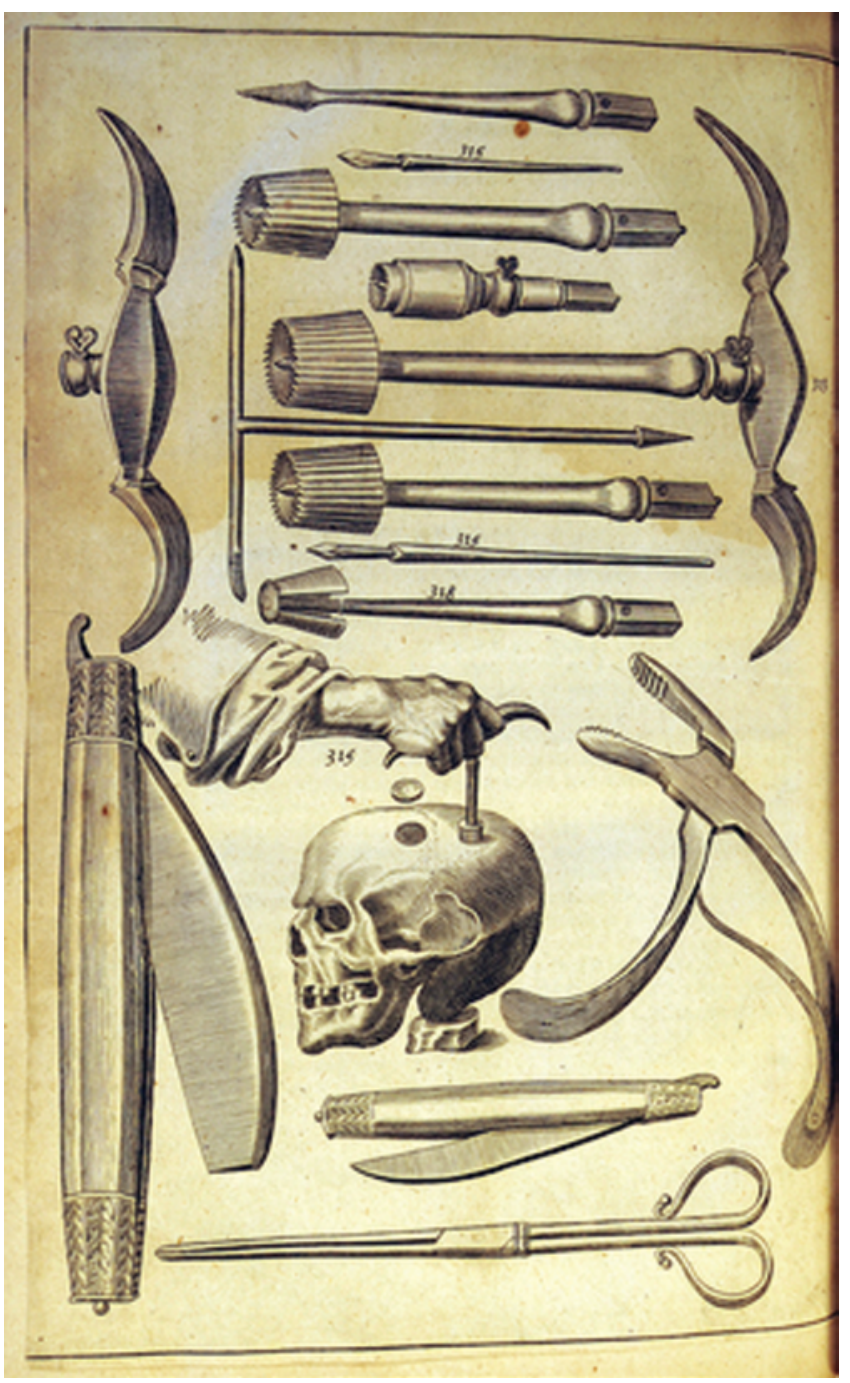

FIG. 11. Woodall's "hand"-style trephine along with the interchangeable burs, all with triangular shapes to prevent plunging. From Woodall $\mathrm{J}$ : The Surgeons Mate, or Military and Domestique Surgery Discouering Faithfully \& Plainly Ye Method and Order of the Surgeons Chest, Ye Uses of the Instruments . . London: R. Young et al., 1639.

or gull-wing types, depending on the surgeon's wishes and the manufacturer. Within the case would be the trephine handle, interchangeable bits, a bone elevator, a bone brush, a lenticular, a bone grasper, and occasionally forceps. Fig. 14 shows one of the more popular English sets, this one designed by Samuel Sharp, F.R.S. (1709-1778), a Guy's Hospital surgeon. This Sharp set has the "gull wing" style handle on the trephine. As these instruments were produced in the pre-antisepsis era, they were rarely cleaned and often come up for sale still encrusted with the blood and grime of the last surgery.

Surgeons were also becoming more convinced that wounds of the head could prove to be "curable," changing a long-standing philosophy dating back to Hippocrates. An example of this changing view is shown in the writing of an English surgeon by the name of James Yonge (16461721), who published a small monograph titled Wounds of the Brain Proved Curable.... (London, 1682) (Fig. 15). ${ }^{39}$

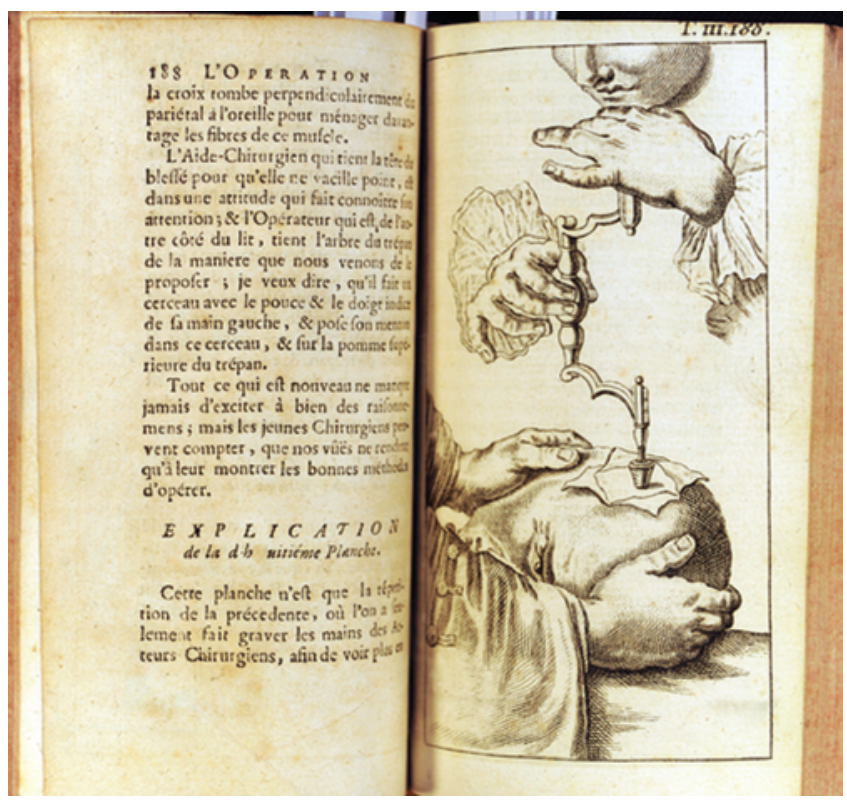

FIG. 12. An illustration of a technique of performing a trephination in which the head and chin rests on the hand-piece thereby applying additional pressure. From Garengeot RJC: Traité des Operations de Chirurgie, Fondé sur la Mécanique des organes de l'Homme, et sur la Théorie \& la Pratiques la plus autorisée. Enrichi de cures tres-singulieres, \& Figures en taille douce, représentant les attitudes des Opérations Seconde Edition, revise, corrigée \& augmentée par l'Auteur. Paris: Chez Huart, 1731

Yonge focused on a 4-year-old child with a skull fracture whom he treated successfully (the child survived). Yonge then goes on to detail another 60 cases from the literature in which he describes patients who survived brain injuryphilosophically a significant leap forward for surgeons.

The 18th century saw further advances in surgical training, with a number of surgeons both in Europe and the United Kingdom attaining university educations. Moving away from the itinerant traveling barber-surgeon, these individuals trained extensively in anatomy and developed much improved surgical skills. An example was Lorenz Heister (1683-1758), who is considered one of the

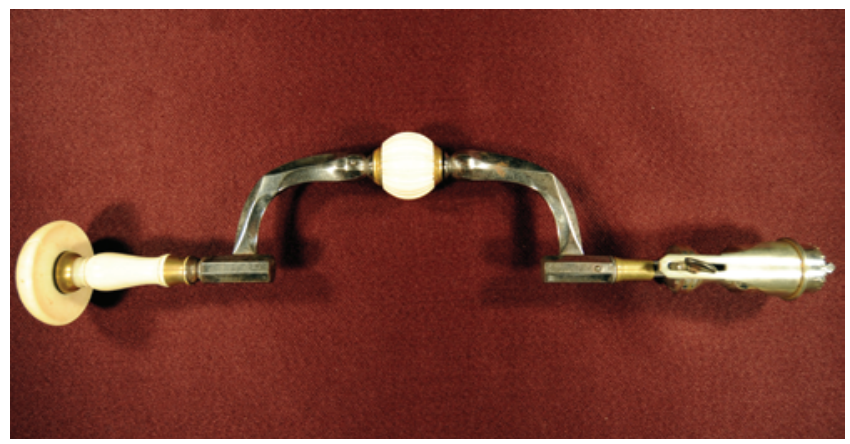

FIG. 13. For the surgeon interested in a more elegant design in the brace-type trephines, European instrument makers could provide these finer styles as illustrated here. This trephine brace was manufactured in Paris by the Galante firm in the mid-18th century. The palm handle and brace swivel are of ivory. The shaft is of polished metal. The bur has an adjustable depth gauge of brass and metal. This item is from the personal collection of the author. 


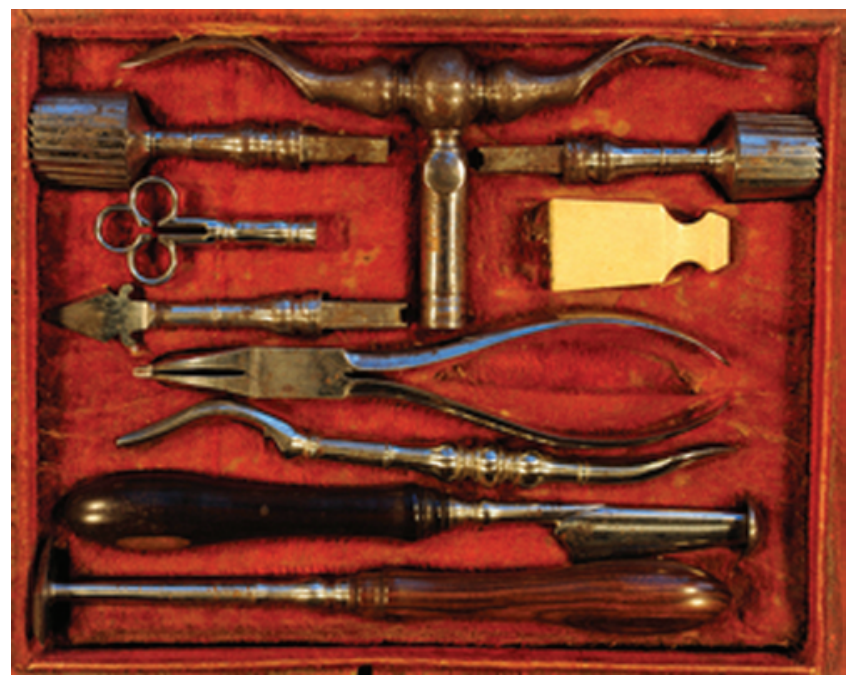

FIG. 14. A mid-18th century traveling trephine set designed by Samuel Sharp with the "gull-wing"-style handle and interchangeable burs. These items are from the personal collection of the author.

founders of scientific surgery. ${ }^{24}$ In addition to having a university education, Heister refined his anatomical skills by studying under the great anatomist Bernard S. Albinus (1697-1747) and improved his medical skills working under Herman Boerhaave (1668-1738). Heister published both surgical and anatomical volumes that became extremely popular and were translated into a number of different languages. In reviewing one of Heister's surgical textbooks we find illustrated his trephination set (Fig. 16). ${ }^{24}$ The trephine brace is of the typical 18th-century style, with a series of interchangeable bits for making bur holes. Heister also introduced an innovative surgical technique for controlling scalp bleeding. Taking a needle and thread he passed the suture through the scalp in a series of overlapping weavings and by cinching it down could reduce the blood loss from the scalp edges.

A prominent 18th-century English surgeon who had a strong interest in head injury and its surgical treatment was Percival Pott (1714-1788). Pott is remembered eponymously for Pott's puffy tumor (osteomyelitis of the scalp) and Pott's disease of the spine, from tuberculosis. In a book on head injuries, Pott reveals his knowledge of the surgical literature and details his experiences..$^{33,34} \mathrm{~A}$ dramatic turn in surgical management of the skull and brain occurs with changes in both concepts and treatment techniques. In the section under trephines, Potts cites the writings of Hippocrates, Galen, Andrea della Croce, and Albucasis (Abul Qasium), all surgeons discussed previously. Pott notes that he clearly disagrees with their earlier surgical treatment, or the lack thereof. He argues that in the treatment of skull fractures the blood and pus that accumulate under the skull need to be removed. Pott points out that the symptoms seen in head injury are due to direct injury of the brain and not due to just skull injury. Pott also details the difference between compression and concussion when evaluating a head injury. Pott is critical of earlier techniques and instrument design in regard to the trephine. Pott comments that he can make a hole in the head with only a trephine, an elevator, and

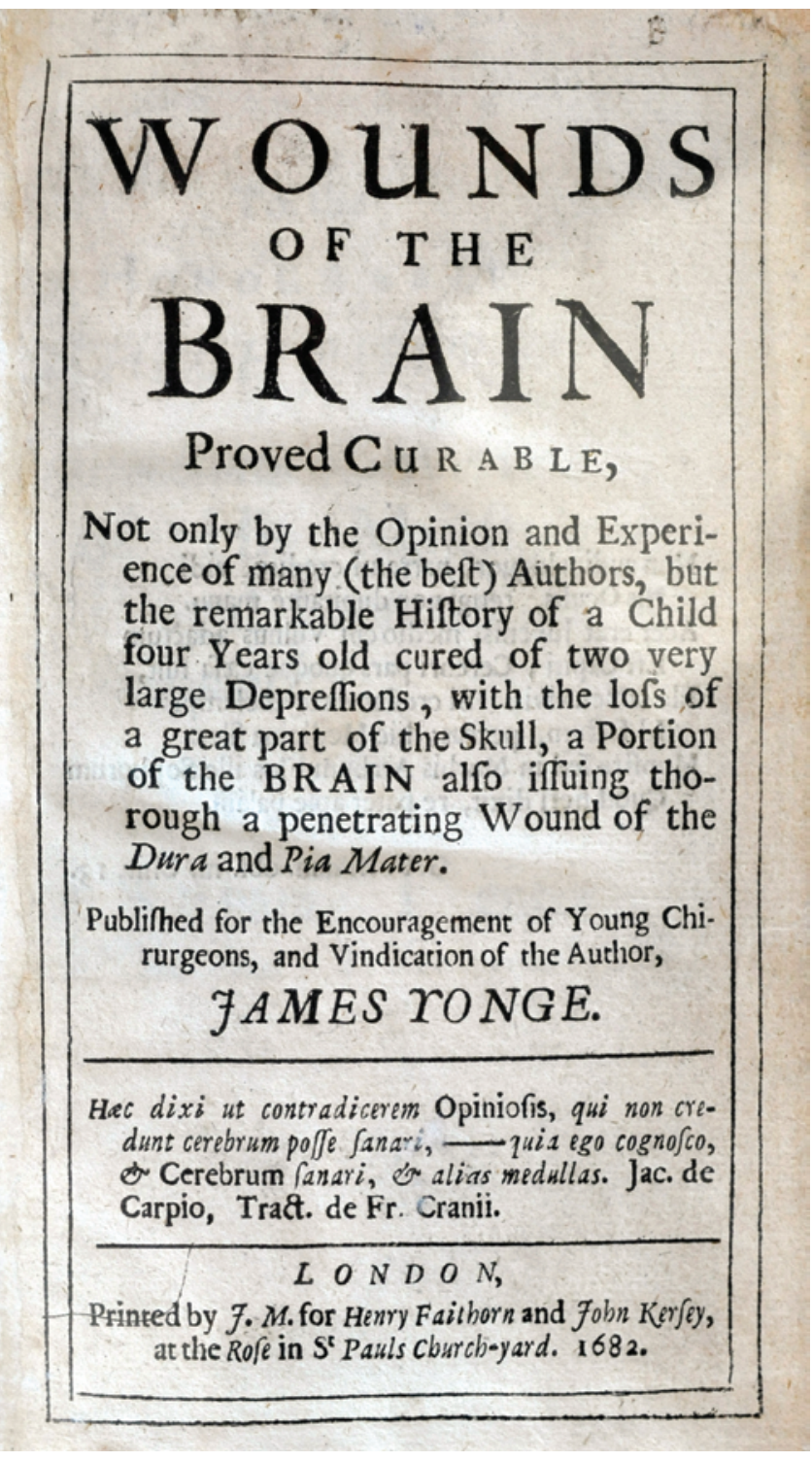

FIG. 15. Title page from James Yonge's monograph on wounds of the brain-a work that reflects a change in thought in this era in that brain and skull surgery could be done and the patient could survive the intervention. From Yonge J: Wounds of the Brain Proved Curable, Not Only by the Opinion and Experience of Many (the Best) Authors, but the Remarkable History of a Child Four Years Old Cured of Two Very Large Depressions, With the Loss of a Great Part of the Skull, a Portion of the Brain Also Issuing Thorough a Penetrating Wound of the Dura and Pia Mater. London: Henry Faithorn and John Kersey, 1682.

occasionally he might need a forceps. Pott favored the "tripod" style trephine illustrated in Fig. 17. In Fig. 17 is also illustrated Pott's ingenious technique for elevating a pediatric skull fracture using a corkscrew-type device with a lever arm. ${ }^{34}$

By the beginning of 19 th century we find the trephine sets moving more toward the smaller hand-held T-style trephines. Several sizes of burs were often included in the set along with the obligatory bone dust brush. These traveling sets also included elevators, bone forceps, and lenticulars (used for scraping soft tissue off the skull). For the surgeon with a more robust budget, more safety op- 


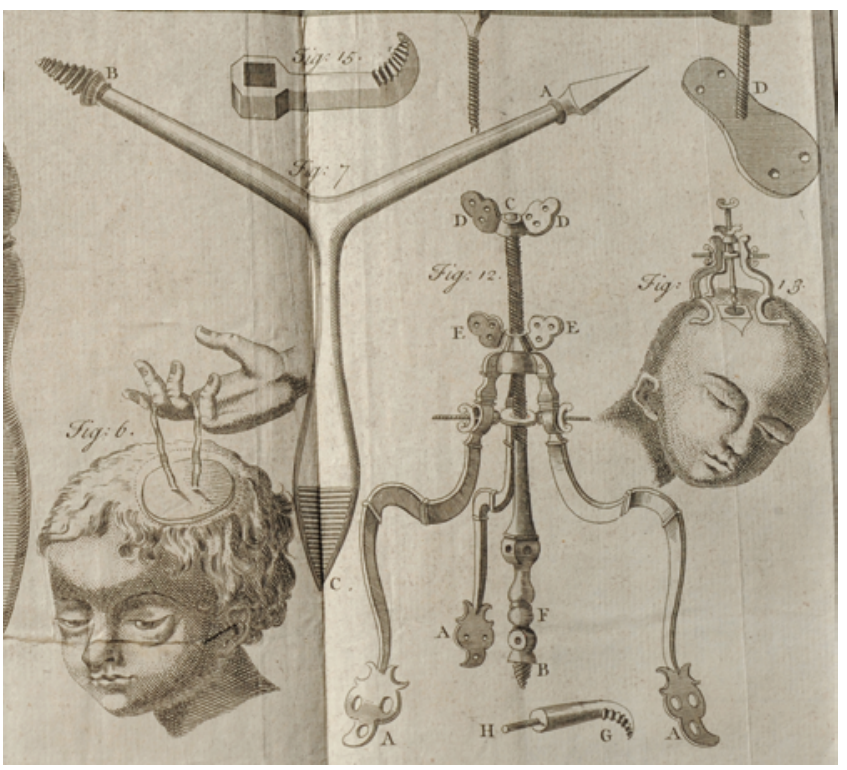

FIG. 16. An engraving from Lorenz Heister's textbook on surgery showing the trephination devices that he used. Illustrated here is an elegant example of the "tripod" style. In addition is illustrated a "threewinged" type of bone elevator that is screwed into the bone. The lower left demonstrates an ingenious way to elevate a pediatric "ping-pong" fracture. A piece of leather is placed and glued over the depression, allowed to dry and then pulled up with the leather straps. From Heister L: A General System of Surgery, in three parts. Containing the Doctrine and Management I. Of Wounds, Fractures, Luxations, Tumors, and UIcers of all Kinds. II. Of the several Operations performed on all Parts of the Body. III. Of the several Bandages applied. London: Printed for W. Innys et al., 1748.

tions were added to the T-style trephine, the most common being an outer depth gauge that prevented the surgeon from going too deep and plunging into the brain. Different examples of typical trephine sets of this era are shown in Fig. 18.

A variation on the theme of the T-style trephine was introduced by Samuel Coker, F.R.C.S. (Ireland), in 1791. Coker was a surgeon from Ireland who came up with a style of trephine that he thought would allow for easier and safer trepanning of the skull. In addition to the standard "T" handle, he added a "lever"-style handle to provide for an easier method of making a bur hole (Fig. 19). Although it was not as popular as the T-handled type, there were nevertheless a number of variations offered over the next 100 years.

In the latter half of the 18th century bone saws were becoming more commonly used for performing a craniectomy. One of the more popular styles was introduced by a British surgeon at the Leed's General Infirmary by the name of William Hey, F.R.S. (1736-1819), and is now called the Hey saw. By performing a series of parallel cuts a surgeon could remove a square or rectangular piece of bone from the skull. These saws were still being manufactured in a steel format well into the 1940s. The original style was a handle saw with a beveled blade on one side and a beveled or curved edge on the other side. Later adaptations included a sliding depth gauge with a screw adjustment. This gauge allowed the surgeon to predetermine how deep a cut he wanted to make. These saws were

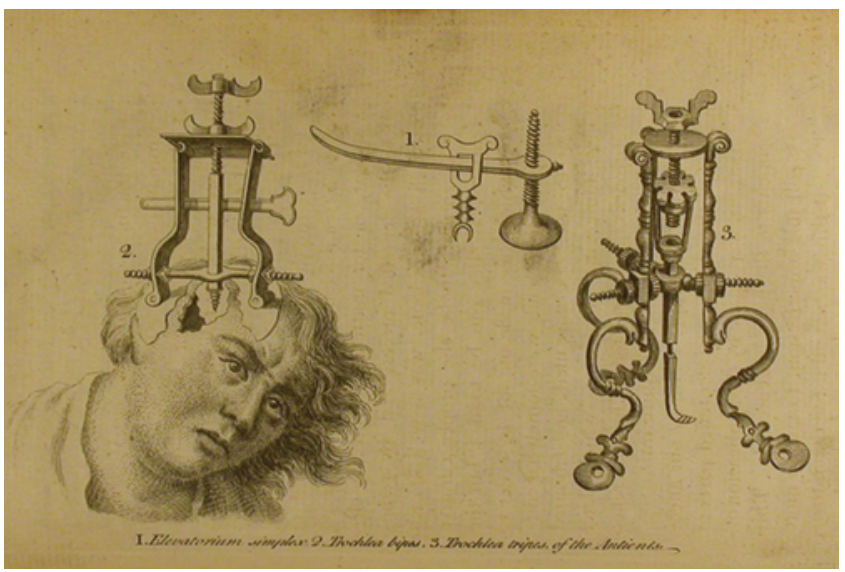

Fig. 17. A illustration from Pott's work on head injuries detailing the "tripod" style of trephine that he favored-a style also quite popular in Europe at this time. An alternative option to elevating a depressed skull fracture is illustrated in the middle image. A "corkscrew" device is driven into the fracture, and then, using a lever arm, the fracture is elevated upwards. From Pott P: The Chirurgical Works of Percival Pott. London: Hawke, W. Clarke, R. Collins, 1775.

commonly added to the 19th-century traveling trephine sets. Two examples of Hey's saw along with a craniectomy osteotome are shown in Fig. 20.

With the close of the 18th century, surgeons interested in operating on the skull and brain were clearly becoming more adventurous and better skilled at the art of doing a trephination, and they were even considering operations directly on the brain. But to make brain surgery safer and more of a skilled art, 3 important developments were needed, and these all occurred in the mid to latter half of the nineteenth century. The introduction of anesthesia (painless surgery), antisepsis (reducing the then very high rate of infection prevalent in all surgeries), and
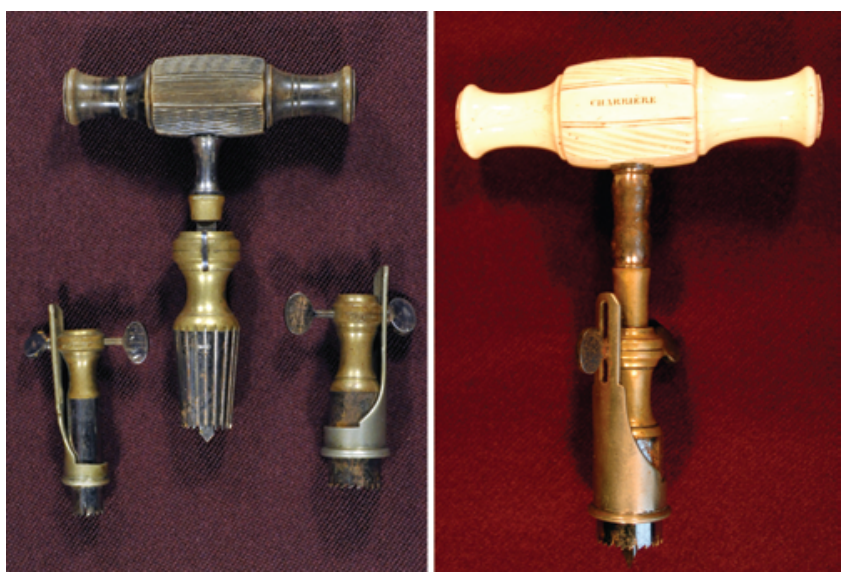

FIG. 18. Left: A more elaborate T-style trephine with some additional safety features to prevent a too deep bur hole. This depth gauge slides over the bur and, tightening the screw, holds it in position. There are 3 interchangeable burs for pediatric or adult patients. Right: For the fashionable surgeon with some wealth, manufacturers could provide trephine examples, such as this one by a French instrument maker by the name of Charrièrre. The handle is made of ivory. The shaft is bronze and the bur a nickel-plated metal. An adjustable depth gauge is provided for the surgeon to prevent plunging and brain injury. These items are from the personal collection of the author. 


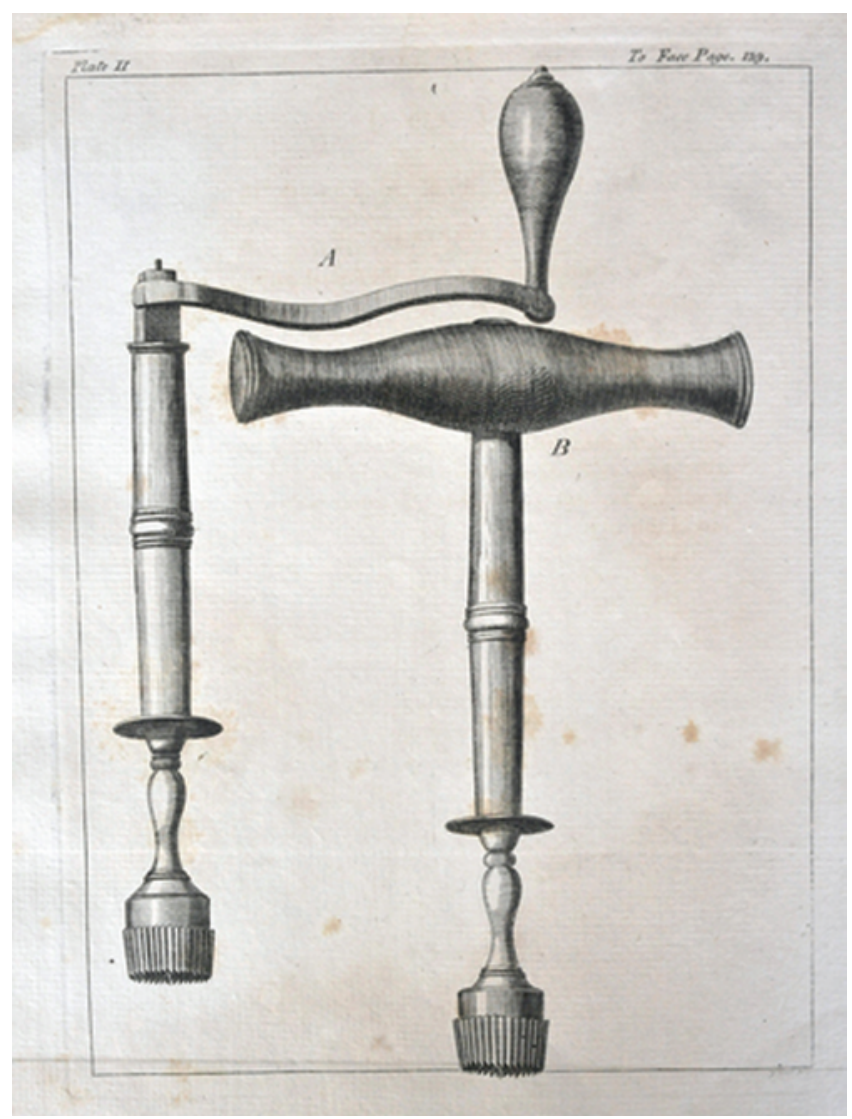

FIG. 19. The "lever"-style trephine introduced by Samuel Coker in the 1790s - a style of instrument thought to be safer and easier to use when trephining a skull. Image from the author's collection.

cerebral localization-these were the 3 key factors that allowed general surgeons to become "neurosurgeons." Without cerebral localization it was impossible to localize a surgical location for an intracranial lesion. In the 1880 s, neurologists and surgeons began working together for a common goal, the removal of brain and spine tumors. As the specialty of neurosurgery began to develop and flourish, surgeons needed to design larger and better skull and skin flaps. The historical technique of connecting a series of drilled holes-chiseling or scraping away the overlying bone-was no longer a satisfactory option.

An example of how a patient was prepared for surgery at the end of the 18th century was detailed by Charles Bell (1774-1842), one England's great surgeons. In reviewing this surgical scenario one can only be grateful to be alive today with the many forms of anesthesia that are now available for "painless" surgery. Bell comments:

Let the bed or couch on which the patient is lying be turned to the light-have the head shaved - put a wax-cloth on the pillow-let the pillow be firm, to support the patient's head. Put tow [sic] or sponge by the side of the head-let there be a stout assistant to hold the patient's head firmly, and let others put their hands on his arms and knees.?

In a remarkable book with hand-colored illustrations, Bell detailed his technique of performing a trephination. ${ }^{7}$ Most of his surgeries were done for traumatic injuries; an example is shown in Fig. 21.

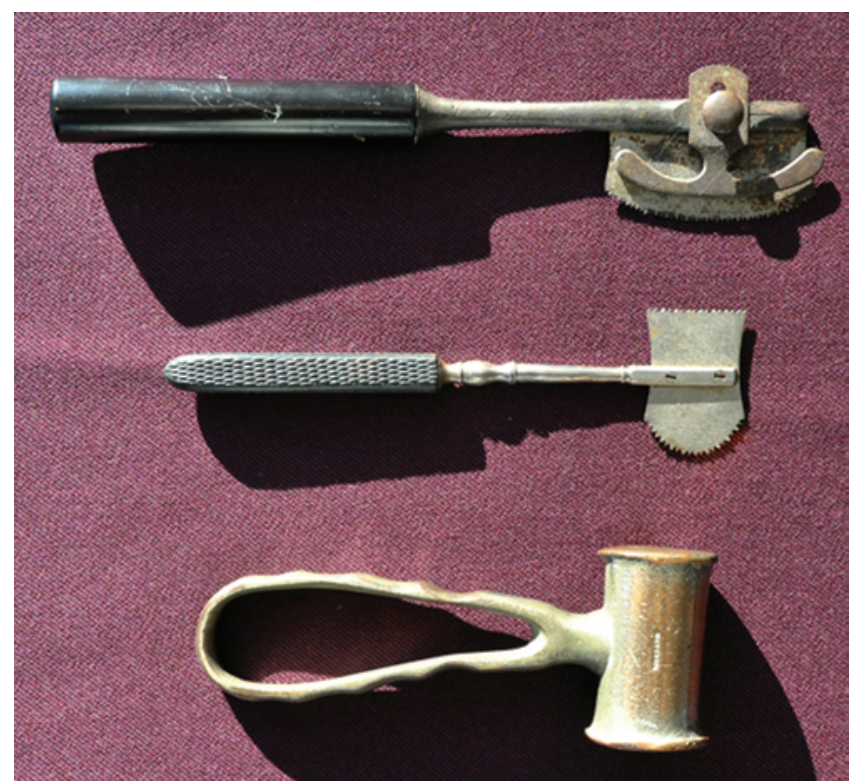

FiG. 20. Two examples of a Hey saw and one of a bone mallet to be used with an osteotome or chisel. The middle saw is an early example, while the upper one shows a more elaborate design with a depth gauge added for dural protection. The lower instrument is a mallet or hammer used with a chisel to perform a craniectomy - a standard 19th-century technique. Instruments from the author's collection.

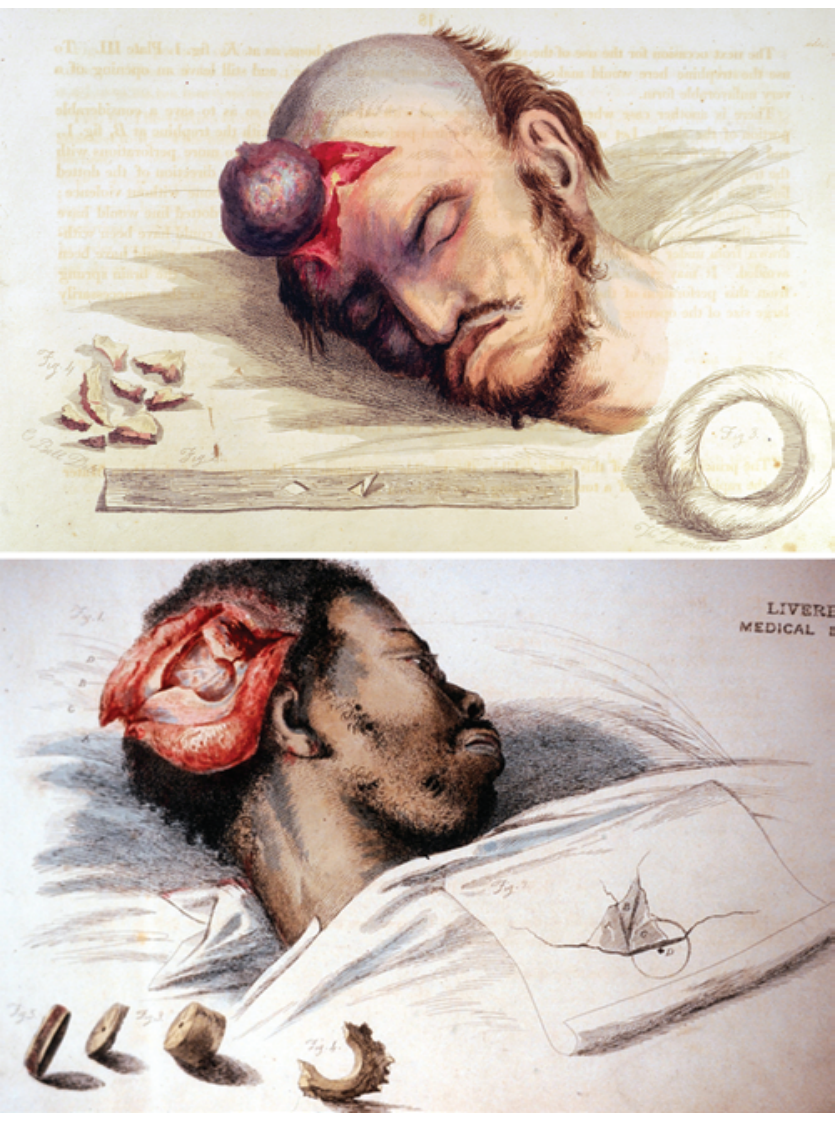

FIG. 21. Two examples of trephinations performed for head trauma from Bell's illustrated book on surgical operations. From Bell C: Illustrations of the Great Operations of Surgery: Trepan, Hernia, Amputation, Aneurism, and Lithotomy. London: Longman, et al., 1821. 
In Bell's text on surgery he gives sage advice to the reader on how to perform a trephination.

The surgeon will expect the instruments to be handed to him in this succession - the scalpel; the raspatory; the trephine; the brush, the quill, and probe, from time to time; the elevator, the forceps, and the lenticular. ${ }^{8}$

An extremely important medical discovery for surgeons was the introduction of antisepsis by Sir Joseph Lister, later Lord Lister, (1827-1912) and others. ${ }^{27,28}$ For the first time, equipment used in an operating room had to be able to be sterilized, typically by boiling water or caustic liquids such as carbolic acid. Craniectomy instruments of the 18th and early 19th century had handles made of wood or ebony, and for the more eminent surgeon, brass and ivory. By the 1880s, trephines and other surgical instruments were being manufactured from more durable materials for sterilization. Manufacturers were changing from ivory, wood, and ebony to "metal" materials, and instruments were often designed with a polished nickel finish (Fig. 22). Surgeons could no longer use materials that could not be immersed in sterilizing liquids or boiling water. While not much changed in surgical design in the early steel trephines, the ability to be cleaned after each case led to tremendous reduction in surgical infections.

To provide a bit of a perspective of what an operating room was like in the era just before antiseptic principles were adopted, I offer this example, as described by an early-20th-century British surgeon reflecting back on the pre-antisepsis era.

Those who have recently joined the profession cannot in any way realize the paralysis of surgery sixty years ago in the presence of suppuration, cellulites, erysipelas, septicaemia, pyaemia, acute traumatic gangrene, and tetanus, for which diseases there was as yet no means of prevention and no remedy.

. The operating theatre (ca. 1875) was of wood. The auditorium would seat several hundred persons. Each of four surgeons had some two hours allotted to him for the performance of the ordinary operations of the week. The surgeon operated in a frock coat which had for a long time been kept in the theatre. It was stained with the blood and pus of previous operations. The

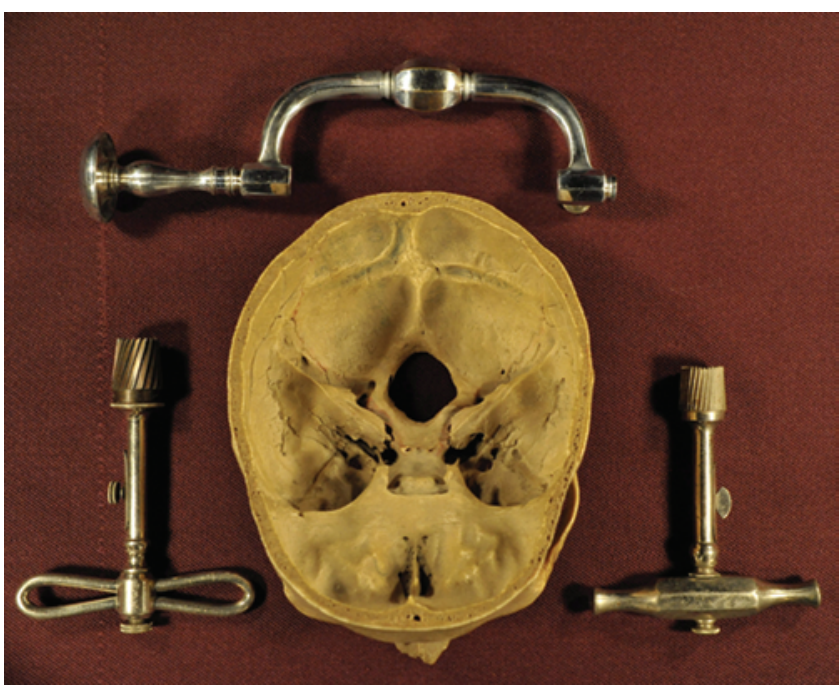

FIG. 22. Trephines from the late 19th century, made entirely of metal. Instruments from this era were often nickel-plated for sterilizing. Items from the author's collection. instruments were placed in a tray lined with green baize. When a ligature was required the theatre attendant would put it on stretch between his teeth and the fingers of the left hand. It was then waxed and handed to the surgeon. ${ }^{6}$

A prominent Philadelphia surgeon at Jefferson Medical College by the name of Joseph Pancoast (1805-1882) published an illustrated surgical textbook in $1844 . .^{32}$ This is an interesting time for surgeons, as this publication date is just before the introduction of anesthesia and antisepsis. In Fig. 23, Pancoast illustrates his technique for performing a craniectomy. Using ungloved and likely unwashed hands, Pancoast demonstrates how to handle a trephine brace to make the bur hole and then enlarge the craniectomy with bone rongeurs. The bone is not replaced, leaving a large skull defect-that is, if the patient survived the operation. Pancoast also demonstrates the technique of holding the T-shaped hand trephine. The shaft is held firmly between the third and fourth fingers. A tight grip is applied to the ebony handle while the hand is rotated in a clockwise direction.

By the end of the 19th century, surgeons began moving away from the debilitating and disfiguring surgery done for craniectomies (for example, the hammer and chisel technique). With "painless surgery" (that is, anesthesia) now available, a surgeon did not have to oper-

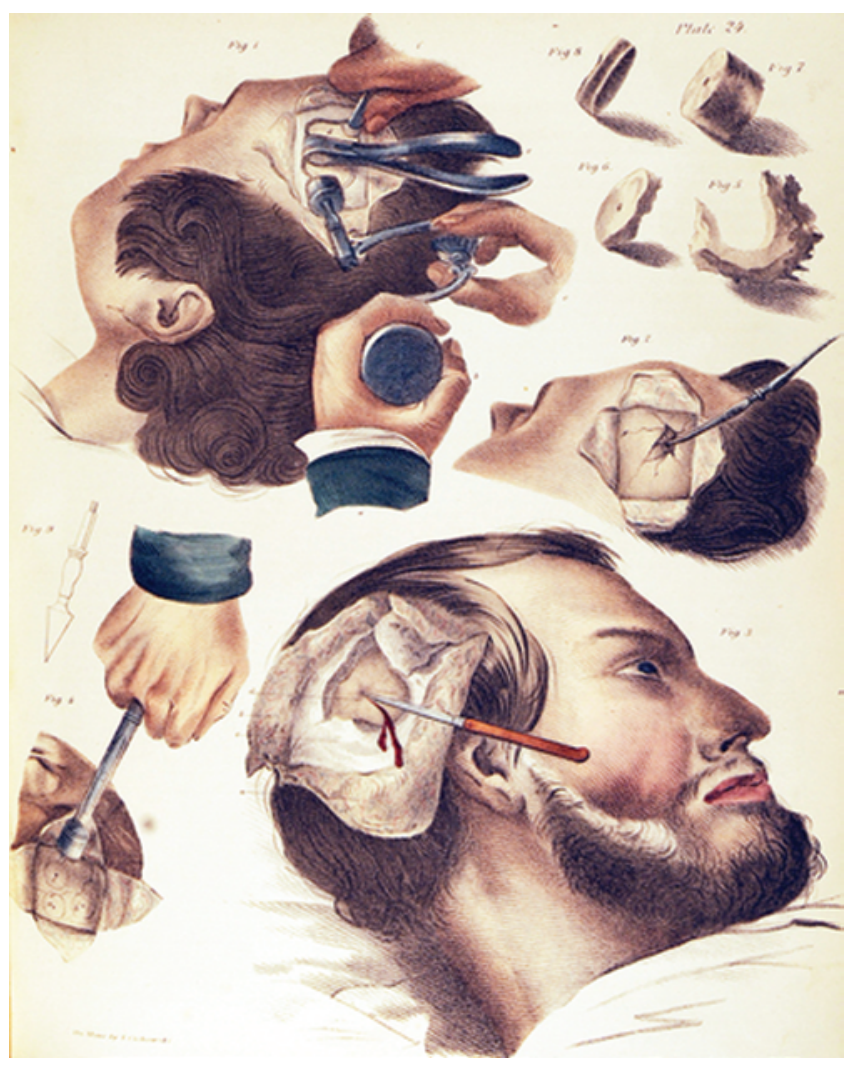

FIG. 23. Illustrations from Joseph Pancoast's 1844 treatise demonstrating how to perform a craniectomy in the preantisepsis era. Note the ungloved hand. The surgeon is also in street attire. From Pancoast $\mathrm{J}$ : $A$ Treatise on Operative Surgery; Comprising a Description of the Various Processes of the Art, Including All the New Operations; Exhibiting the State of Surgical Science In Its Present Advanced Condition. Philadelphia: Carey and Hart, 1844. 
ate at breakneck speak and on an often struggling and scared patient in severe pain. The "hammer and chisel" craniectomy was clearly crude and often damaging to the patient's brain. Trephines were helpful but gave limited access to the brain. With cerebral localization becoming more a common practice in the 1880 s, neurologists were prompting general surgeons to undertake more radical surgeries on the brain, and for this purpose larger craniectomy techniques had to be developed. A radical change in providing a larger exposure of the brain was the introduction of the osteoplastic craniotomy. The osteoplastic flap was designed so that the skull bone was elevated on a pedicle of overlying soft tissues. There were a number of surgeons during this era who developed modifications for an osteoplastic craniotomy. A pioneer in the use of the osteoplastic flap was Wilhelm Wagner (1848-1900). ${ }^{11,31,37}$ Wagner developed the osteoplastic flap to provide more exposure of the brain. In a sign of the times, the Wagner flap was elevated with a hammer and chisel. It is interesting to note that Wagner first developed his flap design by working on cadavers. Despite the use of the hammer and chisel, the osteoplastic craniotomy was clearly much less mutilating and also provided a protective covering for the brain at the end of the operation.

A critical development for the surgeon in elevating a craniotomy was the introduction of the Gigli saw, a flexible wire with barbs fine enough to make a smooth cut in the skull bone. ${ }^{10,23,25}$ Leonardo Gigli (1863-1908) was an obstetrician who originally designed this saw for a lateral pubiotomy to provide a larger opening for delivery in obstructed labor. The idea for this saw came to Gigli during a dinner banquet when he saw a waiter using a "jagged" knife. The design of the original saw (see Fig. 24) was quite different from what is in use today. The original design had ebony handles and thus could not be sterilized. Within a decade the handles were converted to metal. The original saw was flexible in only one direction, as it was a series of linked teeth. Interestingly, Gigli suggested that this saw could be used to cut any bone with the exception of the skull bone. Surgeons quickly realized the saw would work in elevating a craniotomy flap but needed more flexibility so as to be able to pass between 2 bur holes. This led to a design change, in which the saw was changed to flexible wire with barbed teeth projecting out. Surgeons quickly realized that passing a barbed wire over the dura and under bone was not such a good idea. This led a Polish surgeon by the name of Alfred Obalinski (1843-1898) of Krakow to come up with a flexible guide in 1897 (originally made from bone and quickly changed to metal) to which the Gigli saw could be attached..$^{31}$ Attached to the skull side of the guide, the saw could now be safely passed between bur holes without injuring the dura. In recent years the osteoplastic flap has not been so commonly used, rather a free flap has become the norm. As recently as the 1980s the majority of craniotomies were osteoplastic flaps. With the advent of faster and more refined high-speed craniotomies, neurosurgeons now prefer taking the bone flap out and fixating it back at the end of the case (Fig. 24).

Gigli's saw was a wonderful innovation, and it spread rapidly, so much so that by the end of the 19th century the

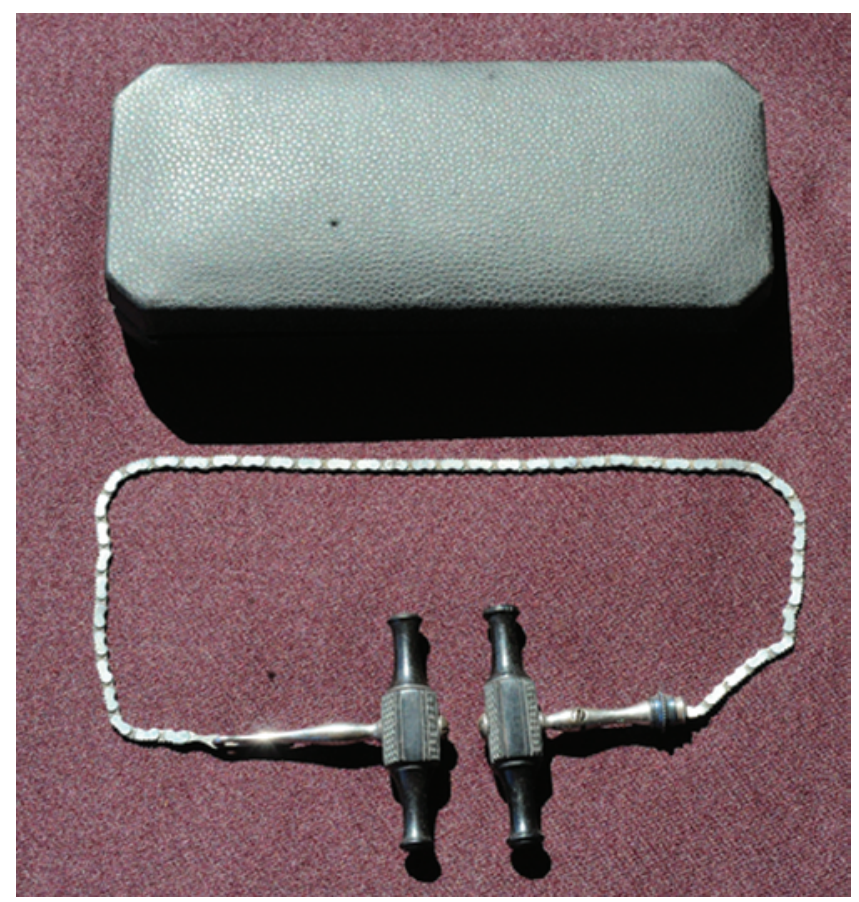

FIG. 24. Gigli's original saw design with the ebony handles. The chain links are barbed but only move in one direction. This design was not suitable for a craniotomy, so it was quickly modified to a wire with barbs that had much more flexibility. From the author's collection.

Gigli saw was in widespread use and was illustrated in many surgical textbooks.

A modification for the Gigli saw was offered by the Parisian surgeon Eugène-Louis Doyen (1859-1916), who designed a unique dural guard for passing the wire saw between the skull and brain. ${ }^{17,18}$ Doyen went on to further contribute to the osteoplastic flap by developing a complex but popular motorized electric saw, which is illustrated in Fig. 25.

The osteoplastic craniotomy rapidly spread throughout the European operating theaters. Just to give some examples, I have picked 3 European surgeons who were significant contributors to early neurosurgery-Fedor Krause, Antony Chipault, and Thierry de Martel.

Fedor Krause (1857-1937) was a giant in early German surgery and neurosurgery. Although he trained as a general surgeon, he rapidly became interested in surgery on the brain and as a result produced one of the earliest and finest illustrated atlases of brain surgery (19091912). ${ }^{26}$ This 3-volume atlas introduced a number of surgical approaches to the brain. To deal with tumors of the pineal region Krause pioneered the supracerebellarinfratentorial approach. Krause was the first to suggest that tumors of the cerebellopontine angle (for example, acoustic neuromas) could be safely operated on. The osteoplastic flap that he designed for the posterior fossa and cerebellum was a true tour-de-force for a surgeon at the turn of the 20th century. Two illustrations from his atlas are shown in Fig. 26. After exposing an acoustic neuroma Krause used an interesting technique of digitally removing the neuroma with an ungloved finger-while it appeared to work for Krause, his complications are not 

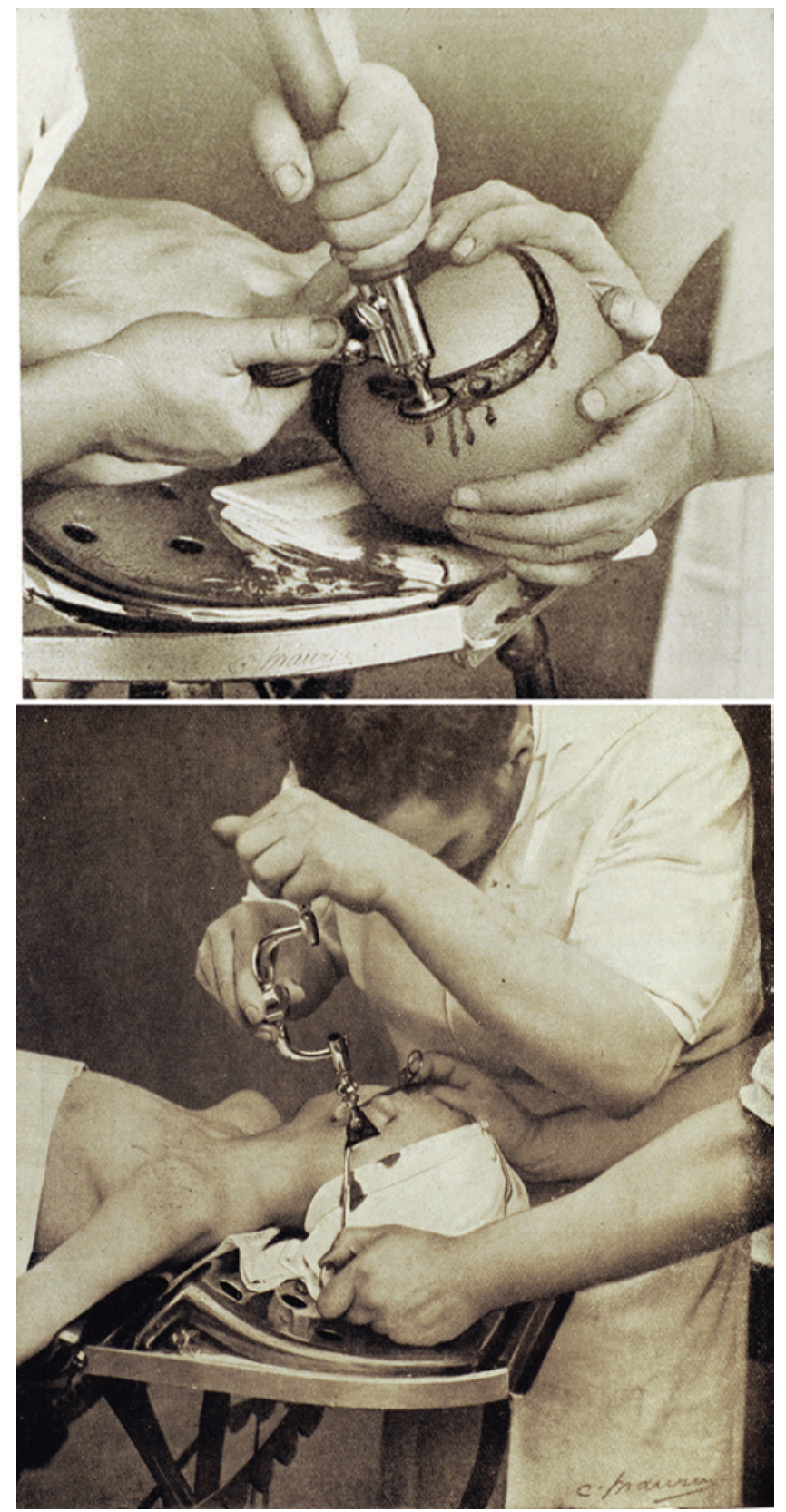

Fig. 25. Neurosurgical illustrations taken from Doyen's textbook on surgery. Upper: Photograph of Doyen demonstrating an osteoplastic craniotomy using a motorized electric drill with a side cutting saw. Lower: Photograph of Doyen demonstrating his trephine technique using a trephine brace that he designed. Note that in these images the surgeon is shown with ungloved hands, no surgical mask, or hair covering. From Doyen EL: Surgical Therapeutics and Operative Technique English edition prepared by the author in collaboration with H. Spencer-Browne. New York: William Wood and Co., 1917.

discussed in his textbook. Krause is best remembered for his quiet demeanor, pleasant personality, and assiduous attention to detail, personality characteristics not common then with surgeons.

Antony Maxine Nicholas Chipault (1866-1920) was the first French surgeon to devote his practice solely to neurosurgery (chirurgien-neurologiste). Chipault had a rather

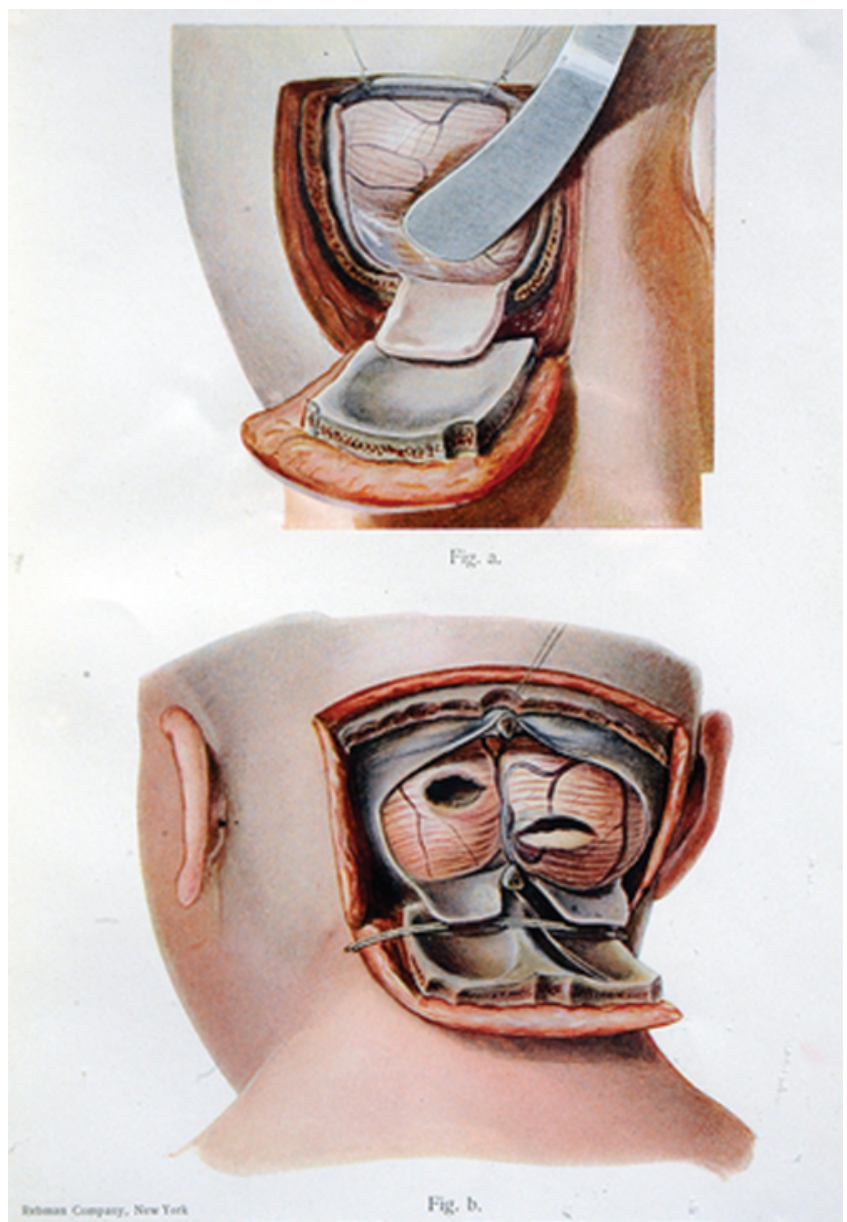

FIG. 26. An elegant illustration of Krause's osteoplastic flap used for a cerebellopontine angle approach. Lower: Illustration showing that Krause accomplishes a surgical tour-de-force with a bilateral cerebellar exposure using an osteoplastic flap. From Krause F: Surgery of the Brain and Spinal Cord Based on Personal Experiences. New York: Rebman Co., 1909-1912.

short academic career and published a number of important papers and monographs dealing with neurosurgery at the turn of the 20th century. At one point he was the head of the surgical clinic at the La Salpêtrière, but only for a short period. The tragedy of this individual was his rapid acceleration in neurosurgery and the equally rapid departure from medicine early in his life, quitting his surgical practice at the age of 39 in 1905. Unfortunately, Chipault's life history still remains an obscure subject of which little is known. Some writers have commented that he appears to have developed early signs of quadriplegia of unknown etiology. In 1894-1895 he published a 2-volume work on surgery of the nervous system in which were introduced a number of new instruments and operative procedures. ${ }^{13}$ Reviewing Chipault's neurosurgical writings shows him to be an early advocate of the osteoplastic craniotomy. Interestingly, the first chapter of his work on the brain includes a then-contemporary historical overview of neurosurgery as perceived by Chipault, including a historical study on the development of trephination back to ancient times. ${ }^{13}$

Chipault was clearly a gifted surgeon and comfort- 
able with operating on either the brain or the spine. One of Chipault's early interests was in a better understanding of cranio-encephalic topography, and he devised some rather ingenious topographs of the head for cerebral localization. What is extraordinary is that Chipault did his first brain tumor in 1892 and then retired in 1905, leaving behind a prodigious output of neurosurgical materialone could only imagine what his contributions would have been if he had been able to continue his surgical career longer. In personality he was described as a very retiring, shy, and very discreet man. (Fig. 27)

Another innovative surgeon at the beginning of the 20th century was the French surgical pioneer Thierry de Martel (1875-1940). De Martel had a particularly strong interest in tumors of the posterior fossa and the cerebellopontine angle. He was trained originally as an engineer prior to going to medical school, and he took advantage of his engineering background to design a number of surgical tools, including one of the first machine-driven trephines. De Martel also designed the first electric motor-driven trephine that "disengaged" when the tip of the bur reached the inner table and dura. Like Doyen, he adopted and further modified the Gigli saw with a metal guide to help pass the saw between bur holes and thereby avoid injury to the brain (Fig. 28). In posterior fossa surgery, de Martel was an early pioneer in the use of the sitting position. He designed his own surgical chair with various positioning devices to correctly position the patient. ${ }^{12,15}$ For almost all of his surgeries he incorporated the osteoplastic flap for craniotomy coverage. Although it is not often appreciated now, de Martel pioneered the technique of intraoperative cinematographic recordings and was among the first to use Kodachrome film to record surgical techniques. De Martel's life was short, as he committed suicide on the day the Germans invaded Paris. He ended his life with a self-injected lethal dose of potassium cyanide.

The difficulties that attend any attempt on the part of the surgeon to expose, much less remove tumors from the cerebellum, differ very materially from those encountered in tumors of the cerebrum. Speaking upon this subject on another occasion, I said it seemed as though, in encompassing the cerebellum with such large cranial sinuses, nature has intimated that this organ was never to be subjected to exposure at the hands of the surgeon. ${ }^{30}$

An influential American surgeon and an early pioneer in neurosurgery was Charles Frazier (1870-1936) of Philadelphia. Frazier trained at the Hospital of the University of Pennsylvania and then went abroad and studied under Ernest von Bergmann and Rudolf Virchow, among other prominent European personalities. Frazier later became professor of surgery at the University of Pennsylvania. Frazier was an early advocate of the aseptic technique and providing a sterile field for surgery. To speed up turnover time in the operating room Frazier would often grab a broom and a mop to help clean up at the end of a surgical case. Review of Frazier's writings shows that he was clearly not an advocate of the craniotomy or the osteoplastic flap when operating in the posterior fossa. He preferred the craniectomy, using the "hammer and chisel," as he felt this was a safer technique for the patient. ${ }^{30}$ In 1926, Frazier introduced the midline "bloodless" inci-
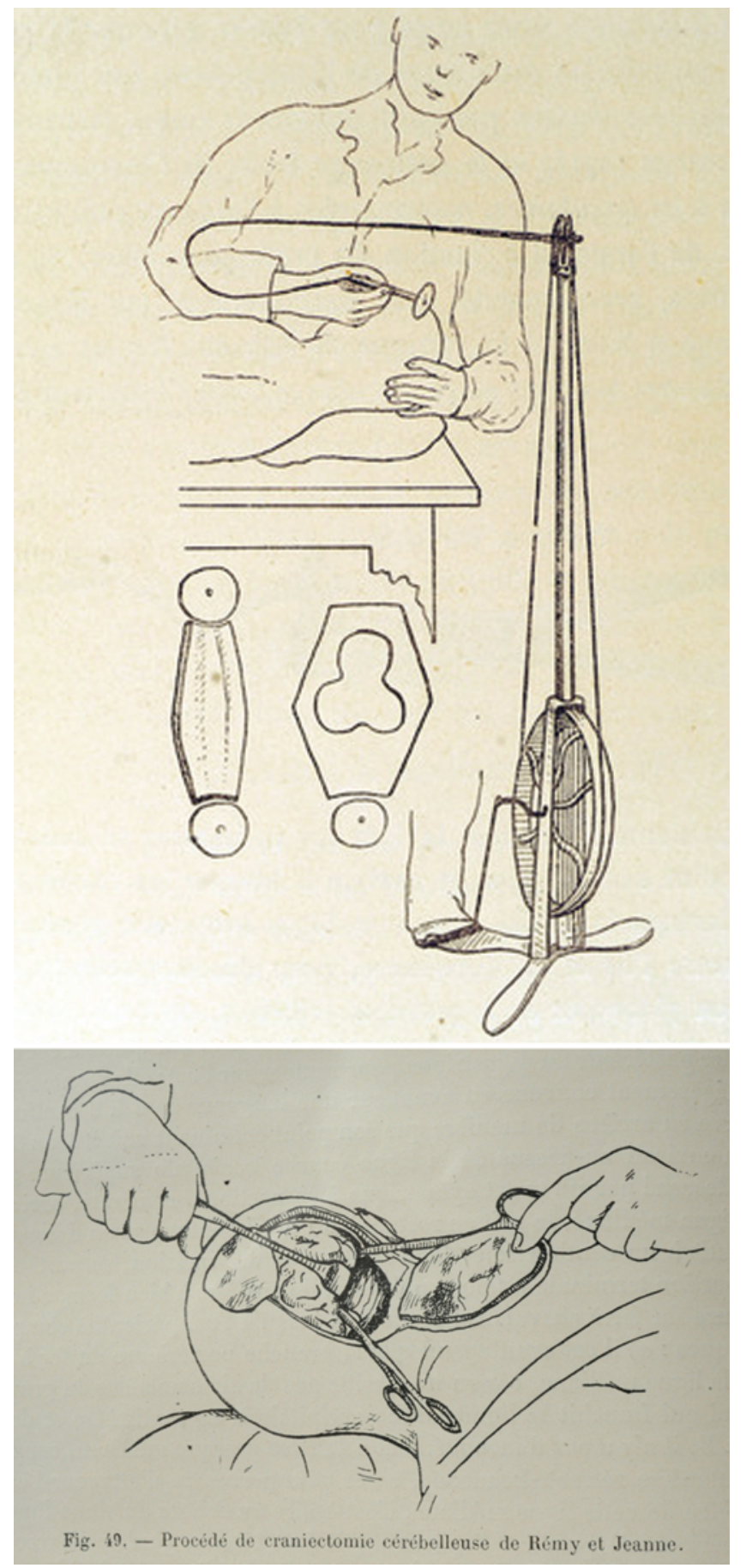

FIG. 27. Upper: Chipault's design for a "surgical engine," which was foot-pedal driven and was used to perform a craniotomy. Lower: Chipault's cerebellar "osteoplastic" flap for exposing the cerebellum. From Chipault A: Chirurgie Opératoire du Système Nerveux. Paris: Rueff et C, 1895.

sion, which extended from the inion vertically to the cervical region. ${ }^{20}$ The incision was a " $\mathrm{T}$ " at the superior end, just above the inion, and then carried down the midline of the neck. Frazier designed this incision to avoid the larger laterally placed occipital blood vessels, which could bleed profusely if surgically disrupted. The skin incision could 


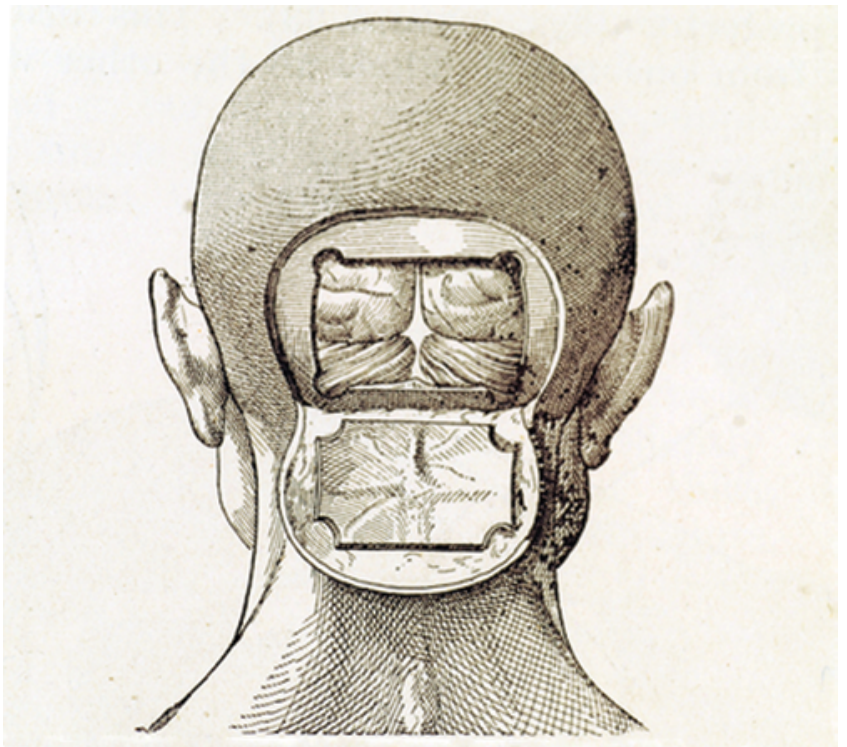

Fig. 34.-In this operation the dura mater separator has had, in order to pass from one to the other of the two lower trephine holes, to insinuate itself between the sinus and internal occipital crest, which is very projecting and quite visible in the figure.

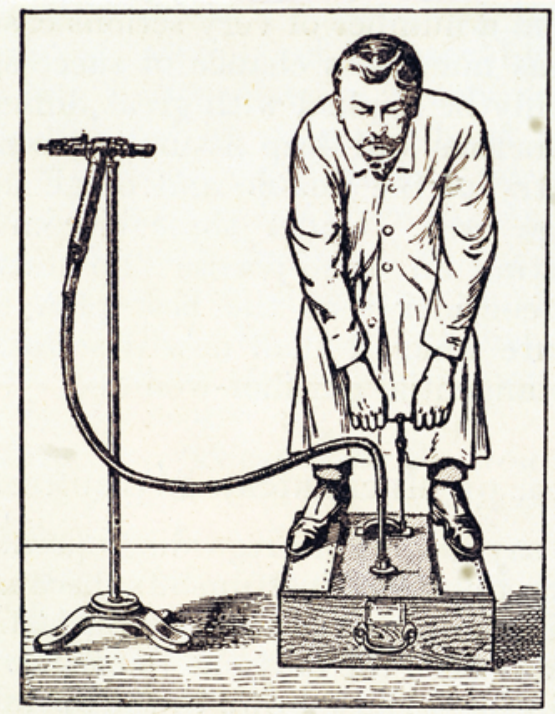

Fig. 45.-The author's motor, which is very strongly made, consists of a horizontal fly-wheel with ball-bearings, and is set in motion by a cog-wheel.

FIG. 28. Upper: De Martel's osteoplastic flap done bilaterally in which the transverse sinus, occipital lobes, and cerebellum are exposed-an aggressive surgical approach for this period. Lower: De Martel was an innovator in surgical engines. With the introduction of electricity and better electrical machines it was now possible to move from hand drilling to machine drilling. Illustrated here is one of the earliest electricpowered craniotomes run by his assistant. Images with original legends from Chatelin CH, de Martel T: Wounds of the Skull and Brain. London: University of London Press, 1918.

be curved and extended more laterally to one side. This additional maneuver would allow Frazier space for placement of a bur hole for CSF removal to decompress the brain, as he realized that most of these patients presented with obstructive hydrocephalus ${ }^{20}$ (Fig. 29).

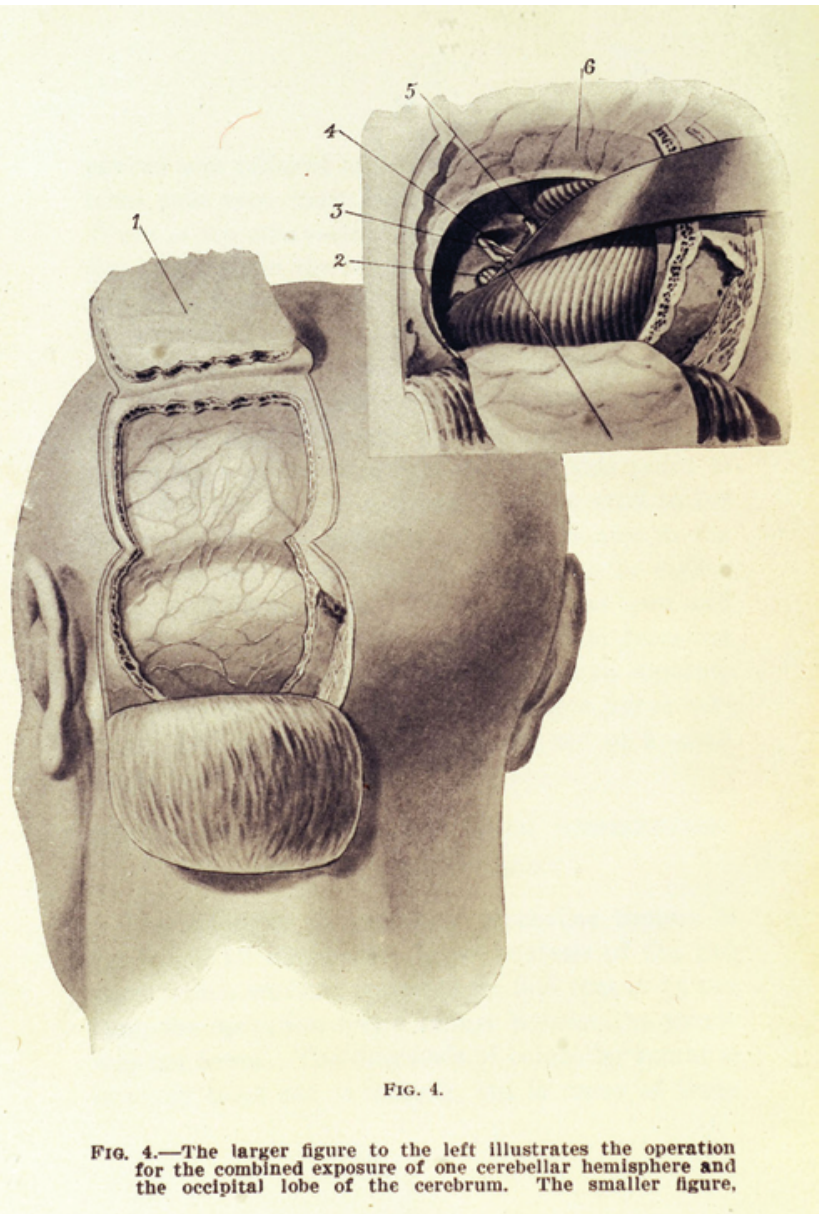

FIG. 29. Charles Frazier's technique for a craniectomy for exposure of the posterior fossa. Frazier recognized the surgical dangers of exposing the transverse and lateral sinuses and the potential for injury to each and as a result preferred not to do an osteoplastic flap, rather he used the "hammer and chisel" to do a craniectomy as shown here in the lower exposure of the cerebellum. From Mills CK, Frazier CH, Schweinitz G, Weissenberg TH, Lodholtz E: Tumors of the Cerebellum. New York: A.R. Elliot, 1905.

In this article, I have been able to review only a few of the neurosurgical pioneers and the osteoplastic surgical flap, electing to stop before the era of Harvey Cushing (1869-1939). It is clear how important just a few people were in putting forth the flap design, designing the necessary surgical instrumentation, and then completing the operation with minimum morbidity and mortality. While the osteoplastic flap is rarely used these days, at the time of its development, the technique was clearly a surgical tourde-force. The reduction in morbidity was significant, not to mention the much less disfiguring skull defects, in comparison with the results of the "hammer and chisel" technique.

\section{Disclosure}

The author reports no conflict of interest.

\section{References}

1. Ægineta P: The Seven Books of Paulus Egineta. Translated from the Greek. With a Commentary Embracing a Complete View of the Knowledge Possessed by the Greeks, 
Romans, and Arabians on All Subjects Connected With Medicine and Surgery. Adams F, trans. London: Sydenham Society, 1847

2. Æginetes P: Opus de Re Medica Nunc Primum Integrum. Köln: Joannes Soter, 1534

3. al-Qasim A: Albucasis on Surgery and Instruments. Spink MS and Lewis GL, trans. Berkeley: University of California Press, 1973

4. Albucasis: Liber Theoricae Necnon Practicae Alsaharavii. Augsburg: Sigismundus Grimm \& Marcus Vuirsung, 1519

5. Avicenna: Liber canonis, de medicinis cordialibus, et cantica. Basel: Joannes Heruagios, 1556

6. Ballance CA: The Lister Memorial Lecture: Delivered in the Theatre of the Royal College of Surgeons in England on April 5, 1933. Dundee, UK: DC Thomson \& Co, 1933, pp 67-68

7. Bell C: Illustrations of the Great Operations of Surgery: Trepan, Hernia, Amputation, Aneurism, and Lithotomy. London: Longman et al., 1821

8. Bell C: A System of Operative Surgery Founded on the Basis of Anatomy, ed 2. London: Strahan and Preston, 1814

9. Berengario da Carpi J: Tractatus de Fractura Calvae Sive Cranei. Bologna: Hieronymus de Benedictus, 1518

10. Brunori A, Bruni P, Greco R, Giuffré R, Chiappetta F: Celebrating the centennial (1894-1994): Leonardo Gigli and his wire saw. J Neurosurg 82:1086-1090, 1995

11. Buchfelder M, Ljunggren B: Wilhelm Wagner (1848-1900). Part 2: The osteoplastic flap. Surg Neurol 30:428-433, 1988

12. Chatelin C, de Martel T: Wounds of the Skull and Brain: Their Clinical Forms and Surgical Treatment. London: University of London Press, 1918

13. Chipault A: Chirurgie Opératoire du Système Nerveux. Paris: Rueff et C, 1895

14. Clowes W: Profitable and Necessarie Booke of Obseruations for all those that are burned with the flame of Gun powder .... corrected and augmented in the yeere of our Lord 1596. London: Imprinted by Edm. Bollifant for M. Dawson, 1596

15. de Martel T: Un point de technique opératoire dans la craniectomie. Presse Med 16:641-643, 1908

16. della Croce GA: Chirurgiae Libri Septem. Venice: Jordanus Zilettus, 1573

17. Doyen EL: La chirurgie du cerveau. Cong Franc de Chir 9:735-740, 1895

18. Doyen EL: Surgical Therapeutics and Operative Technique. Spencer-Browne H, trans. New York: W Wood and Co, 1917

19. Flamm ES: The dilated pupil and head trauma 1517-1867. Med Hist 16:194-199, 1972

20. Frazier $\mathrm{CH}$ : The midline bloodless approach to the posterior fossa. Trans Am Surg Assoc 44:229-247, 1926

21. Galen of Pergamon: Omnia quae extant opera in Latinum sermonem conversa (Quinta ed). Venice: Apud Juntas, 1576-1577

22. Garengeot RJC: Traité des Operations de Chirurgie, Fondé sur la Mécanique des organes de l'Homme, et sur la Théorie \& la Pratiques la plus autorisée. Enrichi de cures tressingulieres, \& Figures en taille douce, représentant les attitudes des Opérations, Seconde Edition, revisée, corrigée \& augmentée par l'Auteur. Paris: Chez Huart, 1731

23. Gigli L: Zur Technik der temporären Schädelresecktion mit meiner Drahtsäge. Zentrabl Chir 25:425-428, 1898

24. Heister L: A General System of Surgery, in Three Parts. Containing the Doctrine and Management. I. Of Wounds, Fractures, Luxations, Tumors, and Ulcers of all Kinds. II. Of the several Operations performed on all Parts of the Body. III. Of the several Bandages applied. Translated into English from the Latin of Dr. Laurence Heister, ed 3. London: Printed for W. Innys et al, 1748
25. Keen WW: On the use of the Gigli wire saw to obtain access to the brain. Phila Med J 1:32-33, 1898

26. Krause F: Surgery of the Brain and Spinal Cord Based on Personal Experiences. Haubold $\mathrm{H}$ and Thorek M, trans. New York: Rebman Co, 1909

27. Lister J: On a new method of treating compound fractures, abscess, etc., with observations on the conditions of suppuration. Lancet 1:326-329, 357-359, 387-389, 506-509; Lancet 2:95-96, 1867

28. Lister JB, Cameron HC: The Collected Papers of Joseph, Baron Lister. Oxford: Clarendon Press, 1909

29. Lowe P: A Discourse of the Whole Art of Chyrurgery. Wherein is Exactly Set Down the Definitions Causes, Accidents, Prognostications, and Cures of All Sorts of Diseases, both in Generall and Particular, Which at Any Time Hertofore Have Been Practiced ... Whereunto is Added the Rule of Making Remedies Which Chyrurgions doe Commonly Use, With the Prefaces of Divine Hippocrates. The Fourth Edition, Corrected, and Much Amended.London: R Hodgkinsonne, 1654

30. Mills CK, Frazier CH, De Schweinitz GE, Weissenberg TH, Lodholtz E (eds): Tumors of the Cerebellum. New York: AR Elliot, 1905, p 41

31. Obalinski A: Zur Technik der Schädeltrepanation. Zentralbl Chir 24:852-859, 1897

32. Pancoast J: A Treatise on Operative Surgery; Comprising a Description of the Various Processes of the Art, Including All the New Operations; Exhibiting the State of Surgical Science in Its Present Advanced Condition. Philadelphia: Carey and Hart, 1844

33. Pott P: Observations on the Nature and Consequences of Wounds and Contusions of the Head, Fractures of the Skull, Concussions of the Brain. London: C Hitch and L Hawes, 1760, pp x-xi

34. Pott P: The Chirurgical Works of Percival Pott. London: Hawk, W Clarke, R Collins, 1775

35. Roger of Salerno: Practica chirurgiae, in: Guy de Chauliac Cyrurgia ... et Cyrurgia Bruni, Teodorici, Rolandi, Lanfranci, Rogerii, Bertapalie. Venice: Bernardinus Venetus de Vitalibus, 1519

36. von Gersdorff H: Feldtbuch der Wundartzney. Strassburg: J Schott, 1517

37. Wagner W: Die Temporäre Resektion der Schädeldaches an Stelle der Trepanation. Centralbl Chir 16:833-838, 1889

38. Woodall J: The Surgeons Mate, or Military and Domestique Surgery Discouering Faithfully \& Plainly Ye Method and Order of Ye Surgeons Chest, Ye Uses of the Instruments... With a Treatise of Ye Cure of Ye Plague. London: $\mathrm{R}$ Young et al, 1639

39. Yonge J: Wounds of the Brain Proved Curable, Not Only by the Opinions and Experience of Many (the Best) Authors, but the Remarkable History of a Child Four Years Old Cured of Two Very Large Depressions, With the Loss of a Great Part of the Skull, a Portion of the Brain Also Issuing Through a Penetrating Wound of the Dura and Pia Mater. London: Henry Faithorn and John Kersey, 1682

Manuscript submitted December 1, 2013.

Accepted February 25, 2014.

Please include this information when citing this paper: DOI: 10.3171/2014.2.FOCUS13543.

Address correspondence to: James Tait Goodrich, M.D., Ph.D., Division of Pediatric Neurosurgery, Children's Hospital at Montefiore, Albert Einstein College of Medicine, 111 E. 210th St., Bronx, NY 10467. email: james.goodrich@Einstein.yu.edu. 